\title{
Variance Risk Premia on Stocks and Bonds
}

\author{
Philippe Mueller
}

Andrea Vedolin
Petar Sabtchevsky

Paul Whelan

\begin{abstract}
We study equity (EVRP) and Treasury variance risk premia (TVRP) jointly and document a number of findings: First, relative to their volatility, TVRP are comparable in magnitude to EVRP. Second, while there is mild positive co-movement between EVRP and TVRP unconditionally, time series estimates of correlation display distinct spikes in both directions and have been notably volatile since the financial crisis. Third $(i)$ short maturity TVRP predict excess returns on short maturity bonds; (ii) long maturity TVRP and EVRP predict excess returns on long maturity bonds; and (iii) while EVRP predict equity returns for horizons up to 6-months, long maturity TVRP contain robust information for long run equity returns. Finally, exploiting the dynamics of real and nominal Treasuries we document that short maturity break-even rates are a power determinant of the joint dynamics of EVRP, TVRP and their co-movement. We argue this result is consistent with an economy in which derivative markets embed fears about deflation.
\end{abstract}

Keywords: Variance Risk Premia, Implied Volatility, Realized Volatility, Covariation, Stocks, Bonds.

This version: February 2017

Philippe Mueller, Andrea Vedolin, and Petar Sabtchevsky are at the London School of Economics. Paul Whelan is at Copenhagen Business School. We thank Ahn Lee, Henrik Hasseltoft, Christian Schlag, Anders Vilhelmsson, Federico Gavazzoni, Ilaria Piatti, George Skiadopoulos, and seminar and conference participants at Lund Young Nordic Finance scholars workshop, Bank of England, SGF Zurich, FMA Helsinki, Multinational Finance Society Conference, EFiC 2016 Conference in Banking and Finance, UBC Summer Conference, EFA (Oslo), SAFE Asset Pricing Workshop, Imperial Hedge Fund Conference, and AFA (Chicago) for thoughtful comments. Paul Whelan gratefully acknowledges financial support from the Center for Financial Frictions (FRIC), grant no. DNRF102 The usual disclaimer applies. Emails: p.mueller@lse.ac.uk, p.s.sabtchevsky@lse.ac.uk, p.s.sabtchevsky@lse.ac.uk, pawh.fi@cbs.dk 
Recent episodes in the United States and Europe have underscored an important link between interest rate expectations, volatility and bond risk premia. For example, measures of option-implied bond market volatility have risen by $60 \%$ between mid-2014 and 2015 in expectation of the Federal Reserve's monetary tightening, fuelling fears of liquidity squeezes in the bond market. Similarly, in Europe, Chairman Draghi announced in summer 2015 that 'we should get used to periods of higher volatility' in an era of low interest rates. Heightened volatility is usually associated with bad economic times and a plethora of research has documented the negative impact of volatility shocks onto the real economy. Compensation for such shocks is measured as the difference between expected variances under physical and risk-neutral measures, otherwise known as the variance risk premium (VRP). Surprisingly, the extant literature studying VRP has almost exclusively focused on equity markets with little attention given to the dynamics of Treasury markets. In this paper we seek to fill this gap.

We document a set of novel facts about Treasury variance risk premia (TVRP), their comovement with the equity variance risk premium (EVRP), and the link between EVRP/TVRP and expected stock/bond returns. First, the premium that investors are willing to pay to hedge against changes in variance in the bond market is smaller in absolute terms than the equity variance risk premium. However, accounting for the volatility of VRP, we document that TVRP are economically comparable to the EVRP. Second, the conditional correlation of stock returns and bond yields switches sign more often than the conditional correlation of stock and bond VRPs. Third, both equity and bond variance risk premia predict equity and bond excess returns at both short (i.e., three months) and long (i.e., twelve months) horizons: $(i)$ short maturity TVRP predict excess returns on short maturity bonds; (ii) long maturity TVRP and EVRP predict excess returns on long maturity bonds; and (iii) while the EVRP predicts equity returns for horizons up to six months, the 30-year TVRP is a formidable predictor at longer horizons. Finally, we present evidence that expected inflation is powerful common denominator of the findings we document. Below we expand on these points.

A first contribution of this paper is to quantify ex-ante variance risk premia for 5-year, 10-year, and 30-year Treasuries, as well as the equity variance risk premium for the S\&P 500 index. The ex-ante variance risk premium is defined as the difference between the expected physical and risk-neutral variances. While the latter can be calculated from the cross section of option prices in a model-free fashion, the calculation of the objective expectation requires some mild auxiliary modelling assumptions. A priori, it is not clear what the best proxy for this objective expectation should be. For example, Andersen, Bollerslev, and Diebold (2007) show that simple autoregressive type models estimated directly from realized returns often perform better than parametric approaches designed to forecast the integrated volatility. In calculating our benchmark bond variance risk premium, we thus use the HAR-TCJ model for realized variance proposed by Corsi, Pirino, and Renò (2010). We augment the model by including 
lagged implied variance as additional regressors 1

Using data which covers the period from 1991 to 2014, we obtain the following results. First, the size of the VRP in the bond market is orders of magnitude smaller than in the equity market in absolute terms. More specifically, while the average equity VRP is -13.48 (monthly and expressed in squared percent), the bond market counterparts are $-3.24,-1.59$, and -0.54 for the $30 \mathrm{y}, 10 \mathrm{y}$, and $5 \mathrm{y}$ Treasury futures, respectively. However, standardising by their volatility in order to study their relative economic magnitude, we find that $\operatorname{TVRP}(5)<$ $\operatorname{TVRP}(30)<\operatorname{TVRP}(10) \sim \operatorname{EVRP}{ }^{2}$

Second, bond market variance risk premia are particularly large during periods of distress which are unique to the bond markets and exhibit less extreme variation in times of distress attributable to equity markets only. To gauge in more detail the difference between the variance risk premia in bond and equity markets, we study their conditional correlation. This observation is important since conditional correlations are a key input into any asset allocation decision. Considering first the correlation between the TVRPs themselves, we find on average large correlations. However, we document a pattern that correlations decrease at the onset of recessions, when the Fed is expected to loosen monetary policy, while correlations increase during recoveries when the Fed is expected to tighten monetary policy. Moreover, this pattern is more pronounced the greater the wedge between maturities. Next, motivated by a vast empirical literature documenting that the correlation between the S\&P 500 index and long-term Treasury returns has changed signs multiple times in the past three decades, we study the co-movement between EVRP and TVRP at different maturities. Interestingly, we find the conditional correlation between bond and equity variance risk premia to be more stable over time. Economically, this implies that relative hedging demand against shocks to bond and equity variance are driven by distinct factors: the pricing of equity variance risk can be large (small) at the same time that the pricing of bond variance risk is small (large). Moreover, we find the conditional correlation between bond and equity VRP to be faster moving than for stock and bond returns.

Third, we study the predictive power of the bond and equity variance risk premium for excess returns on Treasury and equity futures. Considering first a set of univariate predictability regressions we find that the various Treasury variance risk premia significantly predict Treasury and equity futures returns for a wide range of horizons up to twelve months. The statistical significance is also economically relevant. For example, at the 3-month horizon TVRP $(5)$ and TVRP(10) are forecasting 5-year and 10-year futures excess returns with factor loadings

\footnotetext{
${ }^{1}$ Recently, Bollerslev, Sizova, and Tauchen (2012) use a simple heterogeneous autoregressive RV model to construct the stock market variance risk premium while Busch, Christensen, and Nielsen (2011) use the augmented HAR-RV model with lagged IV to improve forecasts of realized volatility. Bekaert and Hoerova (2014) evaluate a series of different models to obtain the "best" estimate of the ex ante equity risk premium.

${ }^{2} \operatorname{TVRP}(\tau)$ denotes the 1-month Treasury variance risk premium on a $\tau$-year bond.
} 
significant at the $1 \%$ level and point estimates that imply a 0.2 standard deviation change in expected excess return for a 1-standard deviation shock to TVRP. We document the predictive power of TVRP(5) and TVRP(10) is particularly strong for shorter maturity futures and shorter horizons while the 30y excess futures return is marginally predictable by TVRP(5) but appears unrelated to other VRPs. Next, we confirm the short run predictive power of the equity VRP for equity excess returns for horizons up to six months. Considering the predictive power of TVRP for equity excess returns we find a surprisingly weak connection to TVRP(5) and TVRP(10). However, the TVRP(30) contains substantial information about expected equity returns for horizons of 6-months and more. For instance, at the 12-month horizon we obtain a factor loading of -0.35 , a t-statistics of -4.36 , and an $R^{2}$ of $12 \%$. Finally, considering a representative set of multivariate regressions we find the predictive power of $\operatorname{TVRP}(5)$ and $\operatorname{TVRP}(10)$ for 5-year and 10-year futures excess returns remains essentially unchanged when adding the equity VRP as a second predictor variable. More interestingly, including both TVRP(30) and EVRP when predicting equity excess returns we find that EVRP remains highly significant up to a 6-month forecasting horizon after which the forecasting power is driven by $\operatorname{TVRP}(30)$. We argue this is an important finding for the literature given the attention devoted thus far in studying short run predictability of equity returns by EVRP.

We also study the predictive power of equity and bond VRPs in multivariate regressions. For equity returns, we find the predictive power of the EVRP and TVRP to be virtually unchanged when we add standard predictors such to the regression. For bond returns, on the other hand, we find well-known predictors such as the slope of the term structure and the Cochrane and Piazzesi (2005) factor already capture the predictive power of TVRP implying compensation for variance risk is spanned determinant of term structure dynamics.

Finally, we provide compelling evidence linking literatures studying the economics of stockbond correlation and variance risk premia. On one hand, motivated by an empirical literature on non-neutrality asset pricing theory has structural models to explain this phenomenon in terms of shocks to inflation being correlated with shocks to the real economy. On the other hand, while a large literature documents the properties of variance risk premia on stocks, there is little consensus of its underlying economic source.

We consider the joint dynamics of variance risk premia, stock-bond correlation, and the co-movement between variance risk premia. Exploiting real versus nominal Treasury dynamics we present reduced form evidence that the inflation (deflation) risk premium is a powerful common determinant. Summarising our findings, we show that a simple linear combination of yield curve factors and a real-time proxy for the inflation risk premium explain between $29 \%$ and $50 \%$ of the variation in variance risk premia across stocks and bonds and display highly statistical significant. At the same time, the inflation risk premium is an important determinant of the stock-bond correlation and the correlation between variance risk premia 
(with highly statistically significant t-stats and - again in conjunction with yield factors- $R^{2}$ ranging between $21 \%$ and $42 \%$ ). Moreover, the economic magnitude of these findings is large.

We argue the inflation risk premium is the common denominator that contains the potential to link the literature on variance risk premia to the literature on the stock-bond correlation since the late 1990s. The intuition for this is as follows: Since the Russian and the LTCM Crisis, the correlation between stocks and bonds has remained largely negative, implying that bonds are considered hedges that command a negative term premium. In such a situation, an increase in the volatility of inflation further depresses the term premia on bonds because of deflationary risks. Moreover, since compensation for volatility risks is also exposed to the same shocks to inflation volatility, this leads to a natural link between the two. At the same time, negative shocks to the inflation risk premium drive down both bond and equity prices and, hence, have a positive impact on the stock-bond correlation. Finally, shocks to the inflation risk premium are positively correlated with demand to hedge volatility risks because these shocks are also common to the underlying assets.

\section{Related Literature}

Our paper relates to two different strands of the literature. The first studies variance risk premia in reduced form. Carr and $\mathrm{Wu}$ (2009) approximate the value of the variance swap on individual stocks using portfolios of options. Martin (2013) studies a simple variance swap which can be robustly replicated even in the presence of jumps. Bondarenko (2014) empirically documents negative and large variance risk premia for the S\&P500. While these papers only focus on variance risk in the equity market, another strand of literature looks at the compensation for volatility risk in the fixed income market. For example, Trolle (2009) reports that shorting variance swaps in the Treasury futures market, generates Sharpe ratios that are about two to three times larger than the Sharpe ratios of the underlying Treasury futures. Choi, Mueller, and Vedolin (2016) empirically document economically large and negative variance risk premia and argue that there are significant returns to variance trading in Treasury markets that are comparable to those earned in the equity variance market. None of these papers studies the joint dynamics of bond and equity variance risk premia.

More recently, Dew-Becker, Giglio, Le, and Rodriguez (2016) explore the term structure of equity variance risk premia and find that the dynamics of the variance risk premia are difficult to reconcile with standard consumption based asset pricing models which could be due to to some market segmentation. In a similar vein, Barras and Malkhozov (2016) explore the equity VRP using options and stock returns and find that while both are driven by the same economic determinants, they are significantly different. The authors interpret their findings as evidence for market frictions between equity and equity option markets. In line with the latter authors, we confirm that equity and bond VRP seem to be driven by similar economic determinants, 
however, our paper is silent on a potential market segmentation between option markets and their underlying.

Our paper is also related to Adrian, Crump, and Vogt (2016) who study the predictive power of equity volatility for stocks and bonds. More specifically, the authors propose a nonlinear relationship between returns and risk which mirrors flight-to-safety. Non-linearities are important as standard predictive regressions using either the VIX or the realised volatility do not reveal any significant results. Using the VIX as a proxy, they find strong predictive power for both stock and bond portfolios at different horizons. Ghysels, Guérin, and Marcellino (2014) find a similar results using a regime-switching model.

We are not the first to study the effect of macroeconomic variables on stock and bond correlation. For example, Li (2002) documents that uncertainty about future inflation and to a lesser extent the real rate are the main drivers of the time-variation in stock and bond correlation. Baele, Bekaert, and Inghelbrecht (2010) estimate a structural regime-switching model and also find that uncertainty about future inflation as well as the equity variance risk premium and stock market liquidity are important determinants of stock and bond correlation. Similar findings are reported in Asgharian, Christiansen, and Hou (2016). Different from these papers, we document that macroeconomic variables also drive the correlation between the variance risk premia in equity and bond markets.

\section{Estimation of Ex-Ante Variance}

In this section, we describe the methods used to estimate the expected physical variance, $\mathbb{E}_{t}^{\mathbb{P}}\left(\int_{t}^{T} \sigma_{u}^{2} d u\right)$, the expected risk neutral variance, $\mathbb{E}_{t}^{\mathbb{Q}}\left(\int_{t}^{T} \sigma_{u}^{2} d u\right)$, and the variance risk premium. The variance risk premium is defined as the difference between the expected physical and risk-neutral variance, i.e.,

$$
V R P^{(\tau)}=\mathbb{E}_{t}^{\mathbb{P}}\left(\int_{t}^{t+\tau} \sigma_{u}^{2} d u\right)-\mathbb{E}_{t}^{\mathbb{Q}}\left(\int_{t}^{t+\tau} \sigma_{u}^{2} d u\right) .
$$

Using real-time expectations of risk neutral and physical variances over a forecasting horizon of one-month, we construct variance risk premium measures for bonds and equities. For Treasuries, we compute a monthly TVRP measure sampled daily beginning in 1991 using options and futures on 5-year, 10-year, and 30-year Treasury notes and bonds. For equities, we follow the extant literature and directly use the squared VIX as a proxy for the expected variance under the risk neutral measure and we calculate the EVRP using high-frequency data on the S\&P 500 index ${ }^{3}$

\footnotetext{
${ }^{3}$ Alternatively, we use high frequency S\&P 500 index futures data to calculate the realized variances and we calculate implied variances using options written on the futures. The difference between the implied variances backed out from options on the index futures and the squared VIX are negligible and all results are qualitatively the same. Given that the VIX is widely used in the literature on equity variance risk premia we choose to the
} 


\section{A. Data}

To calculate implied and realized variance measures, we use futures and options data from the Chicago Mercantile Exchange (CME). We use high-frequency intra-day price data for 5-year, 10-year, and 30-year Treasury notes and bonds futures as well as high-frequency data for the $\mathrm{S} \& \mathrm{P} 500$ index. In addition, we use end-of-day prices of options written on the underlying futures and index, respectively. We have data starting in 1990 until 2014.

At present, Treasury futures are only traded electronically on GLOBEX. However, historically, they were also traded by open outcry and electronic trade data only became available in August 2000. To maximize our time span, we use data from electronic as well as pit trading sessions. We only consider trades that occur during regular trading hours (07:20-14:00 CT) when the products were traded side-by-side in both markets.4 The contract months for the Treasury futures are the first five consecutive contracts in the March, June, September, and December quarterly cycle. This means that at any given point in time, up to five contracts on the same underlying are traded. To obtain a single time series, we roll the futures around the $28^{\text {th }}$ of the month preceding the contract month.

For the equity market, it is rather straightforward to construct investable returns (and excess returns) using the S\&P 500 index or some other stock market index (see, e.g., Goyal and Welch (2008)). However, the same is not true for bond markets where usually hypothetical excess returns are constructed from interpolated zero coupon yields (see, e.g., Cochrane and Piazzesi (2005)). Alternatively, one may consider daily changes in the smoothed zero coupon yield curves. To be consistent across both the fixed income and the equity markets, and in line with the underlying data we use for calculating the Treasury variance risk premia, we use returns on a fully collateralised futures position. These are investable returns since both Treasury and S\&P 500 index futures are very liquid and easily tradable.

$$
\text { [ Insert Table I] }
$$

Table I presents summary statistics for the one-month Treasury and equity futures excess returns as well as for the S\&P 500 index. Note that the summary statistics for both the S\&P 500 index and the S\&P 500 index futures are quite close to each other, indicating that trading in the futures is a viable alternative to going long the stock market index. In fact, the correlation between equity cash index returns and futures returns is around 99\%. The returns on the Treasury futures as well as their volatilities are increasing in the maturity of the underlying. The same is true for both the maximum and the minimum (in absolute terms) monthly excess returns. Moreover, not very surprisingly, Treasury futures returns are less

S\&P 500 index and the VIX for our benchmark results instead of following the exact same approach as for the Treasuries.

${ }^{4}$ Liquidity in the after-hours electronic market is still significantly smaller than during regular trading hours. 
negatively skewed than equity returns and exhibit a slightly lower kurtosis. Compared to the traditional approach of computing returns to zero coupon bonds, at the 1-year horizon, we obtain correlations between our 10-year futures excess returns and 10-year zero coupon excess returns of roughly $90 \%$.

For options, the contract months are the first three consecutive months (two serial expirations and one quarterly expiration) plus the four months in the March, June, September, and December quarterly cycle. Serials exercise into the first nearby quarterly futures contract, quarterlies exercise into futures contracts of the same delivery period. We roll our options data consistent with the procedure applied to the futures $5^{5}$

\section{B. Variance Trading and Variance Risk Premia}

The variance risk premium defined in equation (1) is a theoretical construct as the integrated variance $\int_{t}^{T} \sigma_{u}^{2} d u$ cannot be observed. Instead of forecasting a proxy for the integrated variance that would lead to a proxy for the theoretical variance risk premium we focus on forecasting the empirically relevant realized variance that leads to a realized variance risk premium that a trader can actually earn in the market.

There are a variety of over-the-counter and exchange traded instruments that allow to hedge or gain exposure to variance shocks, probably the most well known of which is the variance swap. In a standard variance swap, the buyer pays the variance swap strike price (or the expected variance under the risk neutral measure) and the seller pays the realized variance at expiry (see, e.g., Allen, Einchcomb, and Granger (2006)). For the S\&P 500 index, the squared VIX is generally interpreted as a measure of expected variance under the risk neutral measure (see, e.g., Martin (2013)) and in practice, the realized variance is calculated using squared daily $\log$ returns.

Martin (2013) shows that VIX ${ }^{2}$ only corresponds to the fair price of a variance swap under unrealistic assumptions (one of them being the absence of jumps in the underlying). Relaxing the assumption of no jumps he then proposes a simple variance swap where the payoff is based on normal returns instead of log returns. However, the VIX can no longer be used as the fair strike price and instead, he defines a new index, the SVIX, and shows that the squared SVIX is the fair strike for this new contract. While the VIX ${ }^{2}$ depends on all the cumulants of the log returns, the SVIX ${ }^{2}$ measures only the risk-neutral variance of simple returns. Thus, Martin (2013) suggests an approach that allows to perfectly replicate a variance contract by changing the definition of the payoff function and by adapting the calculation of the strike price.

Bondarenko (2014) takes a different approach to tackle the problem that standard contracts

\footnotetext{
${ }^{5}$ Detailed information about the contract specifications of Treasury futures and options can be found on the CME website, www.cmegroup.com
} 
cannot be perfectly replicated. He also changes the payoff function but introduces a new specification for the realized variance. Instead of either using the sum of squared log returns (as in the standard contract) or the sum of squared simple returns (as in Martin (2013)), he uses the following definition for the daily realized variance:

$$
\widetilde{R V}_{t, D}=2 \sum_{i=1}^{N}\left(x_{t, i}-\log \left(1+x_{t, i}\right)\right)
$$

where $x_{t, i}=P_{i} / P_{i-1}-1$ denotes the simple return over $\left[t_{i-1}, t_{i}\right]$ and $N$ is the number of observed intra-day returns. Bondarenko (2014) then shows that the resulting payoff can be perfectly replicated for any partition and with jumps in the underlying. This makes the alternative definition of realized variance particularly suitable for real-world applications as continuous re-balancing of the replicating portfolio is infeasible in practice and variance swap payoffs are typically calculated using daily data.

Empirically, Bondarenko (2014) finds that equity market variance risk is priced and the risk premium is negative and large. Choi, Mueller, and Vedolin (2016) use the same specification to introduce a variance swap contract for Treasury volatility and they show how to perfectly replicate the contract under the added assumption of stochastic interest rates. They find that variance risk premia in the bond market are also negative and economically significant.

\section{Physical Variance}

Taken the insights of Bondarenko (2014) and Choi, Mueller, and Vedolin (2016) into account, we focus on forecasting the same specification of realized variance that is relevant from a practical point of view and that can be perfectly replicated under realistic assumptions. However, in most of the existing econometric papers on forecasting variance, the common proxy for the integrated variance is a realized variance measure based on squared log returns. In the following, we first discuss the standard approaches for forecasting realized variance even though in our practical implementation we forecast the $\widetilde{R V}$ defined in equation $(2)$.

The common way to estimate $\mathbb{E}_{t}^{\mathbb{P}}\left(\int_{t}^{T} \sigma_{u}^{2} d u\right)$, the expected (integrated) variance between $t$ and $T$ under the physical measure, is to use empirical projections of the realized variance on some variables in the information set. Our approach is guided by a large empirical literature which documents the following properties of realized variance: First, realized variance features strong persistence and additional information content in the most recent return variances (see, e.g., Corsi (2009)) and second, the presence of potentially differing predictive information in jump versus continuous volatility components (see, e.g., Andersen, Bollerslev, and Diebold (2007) and Corsi, Pirino, and Renò (2010)).

Let us first consider the daily realized variance based on squared log returns which is defined 
as:

$$
\mathrm{RV}_{t, D}=\sum_{i=1}^{N} r_{t, i}^{2}
$$

where $r_{t, i}=\log P_{i}-\log P_{i-1}$ is the intra-daily $\log$ return over $\left[t_{i-1}, t_{i}\right]$ and $P_{i}$ is the futures price at time $t_{i}$. For each day, we sample $r_{t, i}$ between 7:25 and 14:00 CT, i.e. during pit trading hours on CME $]^{6}$ In line with Andersen, Bollerslev, and Diebold (2007), we use five-minute intervals to calculate the one-day realized variance $\operatorname{RV}_{t, D}$.

In the following, we will also make use of normalized weekly and monthly realized variances which are computed from the daily measure as follows:

$$
R V_{t, W}=\frac{1}{5} \times \sum_{j=0}^{4} \mathrm{RV}_{t-j, D}, \quad \text { and } \quad R V_{t, M}=\frac{1}{21} \times \sum_{j=0}^{21-1} \mathrm{RV}_{t-j, D}
$$

To include the presence of jumps, we follow the approach of Corsi, Pirino, and Renò (2010) who document that jumps can have a highly significant impact on the estimation of future variance. Their HAR-TCJ model for forecasting daily realized variance can be expressed as:

$$
R V_{t+1, D}=\alpha+\beta_{D} \widehat{T C}_{t, D}+\beta_{W} \widehat{T C}_{t, W}+\beta_{M} \widehat{T C}_{t, M}+\beta_{J} \widehat{T J}_{t, D}+\varepsilon_{t+1}
$$

where the threshold bi-power variation measure $\left(T B P V_{t}\right)$ is used to estimate the jump component $\widehat{T J}_{t, D}=I_{C-T z>\Psi_{\alpha}} \times\left(R V_{t, D}-T B P V_{t}\right)^{+}$. The continuous component is given by $\widehat{T C}_{t, D}=\mathrm{RV}_{t, D}-\widehat{T J}_{t, D} \cdot 7 \widehat{T C}_{t, W}$ and $\widehat{T C}_{t, M}$ are normalized averages of $\widehat{T C}_{t, D}$.

Such a HAR-TCJ type model can be easily modified, for example, by adding extra covariates that contain predictive power. In our most general specification, we also include current and lagged implied variances as additional predictor variables. Moreover, since our aim is to make real-time predictions of one month realized variance, we implement the forecasting regression using an expanding data sample of daily observations. We require at least one year (or 252 days) of data to make the first true out-of-sample prediction. Given the available sample span, the first variance forecast is available in July 1991. Since we are running the regression in logs, we need to take the transformation bias into account when predicting variances. To avoid the risk of forecasting negative variances, we further modify the regression and run it in logs instead of levels. Then, at every forecasting step, we add one half of the mean squared error to the log prediction before taking the exponential.

Finally, since we follow Bondarenko (2014) and Choi, Mueller, and Vedolin (2016) in using the empirically relevant realized variance that is sampled at the daily frequency instead of the

\footnotetext{
${ }^{6}$ For the S\&P 500 index, we sample the returns between 9:30 and 16:00 ET, i.e. during the NYSE opening hours.

${ }^{7}$ The expression for the threshold bi-power variation, $T B P V_{t}$, is given in Corsi, Pirino, and Renò (2010). We use confidence level $\alpha=99.9 \%$.
} 
unobservable integrated variance, we add a final tweak to the regression specification (4): We replace the future daily realized variance calculated using high-frequency data in the LHS of the regression equation by $\widetilde{R V}_{t+21, M}=\sum_{j=1}^{21} \widetilde{R V}_{t+i, D}$, the one month ahead monthly realized variance calculated using daily data and the definition given in equation (2). In doing so, we forecast the quantities that empirically matter and the resulting ex-ante variance risk premia are consistent with the ex post realizations analysed in Choi, Mueller, and Vedolin (2016). Hence, the regression specification for our benchmark model looks as follows:

$$
\begin{aligned}
\ln \widetilde{R V}_{t+21, M}= & \alpha+\beta_{C, D} \ln \widehat{T C}_{t, D}+\beta_{J, D} \ln \left(1+\widehat{T J}_{t, D}\right)+\beta_{C, W} \ln \widehat{T C}_{t, W}+\beta_{C, M} \ln \widehat{T C}_{t, M} \\
& +\beta_{I V, 0} \ln I V_{t}+\beta_{I V, 1} \ln I V_{t-1} .
\end{aligned}
$$

Note that the regression is run using daily data but the forecasting horizon is one month.

In Panel A of Table [I] we present the summary statistics for our monthly realized variance predictions. For ease of interpretation, we present them as annualised volatilities by taking the square of the variance forecasts and multiplying by the square root of 252 . In line with earlier research, we find that the average realized volatility for the stock market is around $16 \%$ with a standard deviation of $7 \%$. Realised volatilities of bonds are lower ranging between $4 \%$ (for the 5-year Treasuries) and 9.3\% (for the 30-year Treasuries). We note that all four realized volatility measures are highly persistent as indicated by the $\mathrm{AR}(1)$ coefficients close to 0.85 .

$$
\text { [ Insert Table II] }
$$

\section{Implied Variance}

To calculate the expected variance for the Treasuries under the risk-neutral measure, we use a cross-section of options on Treasury futures. We follow Choi, Mueller, and Vedolin (2016) who show how to construct the fair strike price in a Treasury variance swap that is robust to jumps and allows for stochastic interest rates. For the S\&P 500 index we simply follow the extant literature and use the squared VIX 8

In Panel B of Table II, we present the summary statistics for the annualised implied volatilities (i.e., the square root of the variance). The averages are in line with the values for the physical variances but all of them are higher, implying that we expect variance risk premia to be negative on average. The average implied volatility for the stock market is roughly $20 \%$ for our sample period, whereas the implied volatility for the Treasuries ranges between around 4.7\% (5-year Treasuries) and 11\% (30y Treasuries). Similar to the realized volatility measures, implied volatilities are highly persistent with autocorrelation coefficients as high as 0.86 .

\footnotetext{
${ }^{8}$ As previously mentioned, applying the same procedure used for Treasury futures and options to S\&P 500 index futures and options leads to estimates of implied variance that are nearly perfectly correlated with the squared VIX that we are using in the analysis.
} 


\section{[ Insert Figure 1]}

Figure 1 plots the time series of the expected physical and risk neutral volatilities of equities and 30y Treasuries, respectively. Consistent with the extant literature, the magnitude of the spikes in equity volatility is much bigger. For example, during the LTCM crisis of 1998 the annualised realized volatility spikes considerably, whereas the spike in fixed income markets is much more subdued and around half the size of the one observed in equity markets. The same holds true at the time of the Lehman default, 15 September 2008 when implied volatility on the equity index spikes at around $60 \%$, while fixed-income implied volatility was at around $24 \%$.

\section{Descriptive Analysis}

Using the proxies for the expected variances under the physical and the risk-neutral measures introduced in Section $\mathrm{I}$, we now proceed to calculate the ex-ante variance risk premia for stocks and bonds.

\section{A. Basic Properties}

Panel C of Table II reports summary statistics for the equity and Treasury variance risk premia (subsequently denoted EVRP and TVRP, respectively) in monthly terms and expressed in squared percent. As expected, variance risk premia are negative on average both for the equity index as well as the Treasuries. For the S\&P 500 index, the average variance risk premium is -13.5, while for Treasuries, the variance risk premia increase (in absolute terms) from -0.54 for the 5-year to -3.24 for the 30-year Treasury bond futures. In terms of more intuitive volatility risk premia this corresponds to average volatility risk premia of $-4.3 \%$ p.a. for the S\&P 500 index, and $-0.7 \%,-1.3 \%$ and $-1.8 \%$ p.a. for 5-year, 10-year and 30-year Treasuries, respectively. Table $[\mathrm{II}$ also shows that the volatility of variance risk premia varies substantially across assets, increasing in the maturity of the underlying for the Treasury futures with the highest volatility for equity variance risk premia. Given this variability, a better economic comparison between VRP on stocks versus bonds should consider their level standardized by their volatility. Figure 3 plots these statistics alongside standard error bounds computed using a bootstrap procedure, which reveals the relative economic ordering: $\operatorname{TVRP}(5)<\operatorname{TVRP}(30)$ $<\operatorname{TVRP}(10) \sim \mathrm{EVRP}$.

\section{[ Insert Figure 3]}

\section{B. Time-Series Evidence}

It is instructive to compare the time-series dynamics of variance risk premia across stock and bonds. Figure 2 plots monthly sampled one-month variance risk premia with Panel A containing 
the plots of bond variance risk premia while Panel B plots the equity variance risk premia along with the 30-year TVRP for comparison. We note several interesting observations. First, TVRP are almost always increasing in maturity of the underlying bond not only on average but also over time. We also find bond variance risk premia to be countercyclical, meaning they are large (in absolute values) during bad times such as the recent financial crisis (2008-2009), the mortgage refinancing boom (2002-2003) and smaller during normal times.$^{9}$ With regards the comparison of EVRP and TVRP we first note that EVRP are much larger than TVRP. For example during the LTCM debacle and the recent financial crisis, the equity variance risk reaches -60 (in squared percent), while the most extreme variance risk premium in the 30y bond is around -20 observed in August 2013 around the Tamper Tantrum. Second, while the equity variance risk premia as well as the 30-year TVRP are always negative, the 5-year and the 10-year TVRP can sometimes turn positive. Based on data sampled at the monthly frequency, the 5-year TVRP is positive around $9 \%$ of the time while 10-year TVRP is positive less than $1 \%$ of the time. Third, stock and bond variance risk premia display distinct dynamics around noteworthy episodes. The following discussion highlights this point.

$$
\text { [ Insert Figure 2] }
$$

\section{- Case Study 1: A Tale of Equity}

The failure of Long Term Capital Management (LTCM) nearly blew up financial markets, potentially triggering a catastrophe for the global economy. Testifying to this Alan Greenspan, then Chairman of the Federal Reserve, stated that "Had the failure of LTCM triggered the seizing up of markets, ..., and could have potentially impaired the economies of many nations, including our own". Comparing the dynamics of equity versus bond variance risk premia we document a surprising result. While the spike in ex-ante equity variance risk premia is huge a corresponding spike in Treasury variance risk is largely absent. The reason why this is surprising is two-fold: The Federal Reserve facilitated negotiations between LTCM and primary dealers to take over the balance sheet of LTCM after they were unable to fulfill their margin calls. The broker-dealers absorbed a large amount of risk for this event. Second, the reason LTCM blew up was largely due to fixed income statistical arbitrage trading. Indeed, when Russia announced restructuring of its Sovereign bond payments on August 17th 1998, thus defaulting on its debt, LTCM lost over $\$ 500$ million in less than a week.

\section{- Case Study 2: A Tale of Fixed Income}

While the shocks to variance risk premia were largely concentrated in the equity market

\footnotetext{
${ }^{9}$ We formally test the correlation between variance risk premia and observable macro economic variables in a following section.
} 
around the LTCM episode, the 'Taper Tantrum' provides an informative counter example. The Taper Tantrum in the summer of 2013 was largely precipitated by a string of comments on the part of Ben Bernanke, Chairman of the Federal Reserve at the time. In his testimony before Congress in May and June 2013 Bernanke hinted that the Fed would likely start tapering the pace of its bond purchases later in the year, conditional on continuing robust economic data. The ensuing market reaction was dramatic: Long-term U.S. bond yields and dollar FX rates spiked substantially, as did realised stock and bond variance. What is more interesting, however, is the dynamics of risk neutral versus physical variance across stock and bonds. Figure 6 plots the EVRP and the 30 -year TVRP in the aftermath of the Taper Tantrum. Between June and December 2013, the 30-year Treasury variance risk premium increases three-fold as wrong-footed market participants are desperate to hedge their volatility exposure in Treasury markets and willing to pay a premium for this. It is important to note that during this period spikes in variance risk premia are contained in the fixed income markets. Indeed, while equity volatility spikes following Ben Bernanke's statement, the equity variance risk premium does not change much.

\section{Co-Movement}

Motivated by the previous example we now examine the co-movement between stock and bond variance risk premia. We study time-varying correlations between equity and Treasury variance risk premia by estimating a dynamic conditional correlation (DCC) model as follows: First, we estimate a VAR on daily data on all Treasury and Equity VRP levels jointly. ${ }^{10}$ Next, taking the four residual time series from the VAR, we estimate a $\operatorname{DCC}(2,2)$ model via maximum likelihood to extract the time-varying correlations between the various series.

\section{[ Insert Figures 4 and 5 about here]}

To estimate the time-varying correlations for stock and bond returns we use the daily log changes in the respective futures. We plot the resulting correlation series in Figure 4 while Figure 5 displays the dynamic correlation between variance risk premia. In both cases, Panel A plots the correlation between Treasury returns and Treasury VRP, respectively, while Panel $\mathrm{B}$ plots the conditional correlations between equity returns or equity VRP on one hand and Treasury returns or Treasury VRP on the other hand.

The figures show distinctly different patterns. First of all, returns to Treasury futures are highly correlated throughout with correlations close to $90 \%$ on average for all three contracts.

\footnotetext{
${ }^{10}$ We choose 120 lags (roughly six months based on 250 trading days per year) to capture the autocorrelations and cross-autocorrelations in the daily data. However, our results are not materially different if we use a smaller number of lags. In addition, we pre-filter the variance under the risk-neutral measure by taking a monthly rolling average. This removes some of the noise in the implied variance time series.
} 
Second, the correlations between equity and fixed income returns are time-varying with large swings from around $+40 \%$ in the mid 90 s to $-50 \%$ in the early and late 2000s. This pattern is largely in line with the results presented in Campbell, Sunderam, and Viceira (2016) and reflects the changing risks of nominal bonds over time. When considering the variance risk premia, however, different patterns emerge. While correlations among TVRP are still positive throughout, they are considerably smaller compared to the correlations among returns, rarely exceeding 80\%. At the same time, correlations between TVRP and EVRP are also largely positive, although smaller on average: they hover around $20 \%$ with distinct spikes in both directions and they do turn negative occasionally. For example, since the financial crisis the EVRP/TVRP correlation reached a maximum of $60 \%$ and a minimum of $0 \%$ displaying large swings in the run up and following the Taper Tantrum.

\section{Predictive Regressions}

In this section, we investigate to what extent our measures of ex-ante variance risk premia contain predictive power for bond and stock excess returns. In particular, we study the insample predictive power of bond and equity variance risk premia for fixed income and equity excess returns. It is instructive to note that while the predictability regressions we run are in-sample, our proxies for the variance risk premia are constructed without any forward looking bias. More importantly, the predictors we use are observable in real time.

First, we study predictability by running univariate regressions of excess returns on the variance risk premia. As discussed in the previous section, we again use returns on a fully collateralised futures position in either Treasury or S\&P 500 index futures in our predictive regressions. This ensures that both return series are not only investable but also directly comparable. Second, we add commonly used control variables to our univariate regressions to study how robust TVRP and EVRP are for predicting future excess returns.

\section{A. Univariate Regressions}

We run univariate predictability regressions for Treasury futures with underlying maturities between five and thirty years, and for the S\&P 500 index futures. The forecast horizons range between one and twelve months:

$$
x r t_{t+h}^{(i)}=\alpha_{i, h}+\beta_{i, h} V R P_{t}^{(i)}+\epsilon_{t+h}^{(i)},
$$

where $x r t_{t+h}$ denotes the $h$-period excess return and $i$ stands for the VRP (either 5y, 10y, or $30 y$ Treasuries, or the S\&P500 index futures).

All regression results we report are standardised, i.e., we normalise all regressors and regres- 
sands to have a mean of zero and a standard deviation of one. As a result, constants appear nowhere in our specifications. The normalisation not only allows us to compare coefficients across different specifications, but it also helps our interpretation of economic significance. We report $t$-statistics that are calculated using Newey and West (1987) standard errors with twelve lags. Table III summarises the univariate regression results. Panels A through D contain the predictability regressions for the three Treasury and the equity variance risk premia regressions, respectively.

\section{[ Insert Table III]}

Panel A reports the results for the S\&P 500. In line with the extant literature (see, e.g., Bollerslev, Tauchen, and Zhou (2009) and Bekaert and Hoerova (2014)), we find that the equity VRP has significant predictive power for equity returns at intermediate horizons. For example, at the one-month horizon, a one standard deviation (negative) shock to the VRP predicts a 0.13 standard deviation increase in S\&P 500 returns. As we increase the horizon the slope coefficient doubles to 0.25 and 0.24 for the three- and six-month horizon, respectively. For the one-year horizon, the coefficient decreases again to 0.17. Considering the impact of Treasury VRP on equity returns we find that neither the $5 \mathrm{y}$ nor the $10 \mathrm{y}$ variance risk premium have any predictive power for the S\&P 500 at any horizon. However, we do find highly significant and economically relevant predictive power from the 30y VRP for the S\&P 500. For example, we find that while at the one-month horizon there is no predictive power, for the six- and twelve-month horizon, $t$-statistics are -4.15 and -4.36 , respectively. Comparing the economic impact of equity versus 30y VRP, at the 6-month horizon we find a one standard deviation (negative) shock to the $30 \mathrm{y}$ bond variance risk premium raises equity returns by 0.3 standard deviations, which is in fact larger than the impact of equity VRP. To study what happens at horizons longer than one year, we plot in Figure $8 t$-statistics and $R^{2}$ for a horizon of up to two years. The $R^{2}$ for the equity VRP features the well-known hump shape, we note, however, that the $R^{2}$ for the $30 \mathrm{y}$ bond VRP increases with the horizon. In this sense, predictability arising from variance risk premia on very long term bonds more closely resembles price-dividend (long run) predictability than equity variance risk premium (short run) predictability. We study this angle in more detail in the following.

$$
\text { [ Insert Figure 8] }
$$

Panel B presents predictive regression results for the 5y bond returns. We find that the equity variance risk premium has no predictive power for the $5 y$ bond returns at any horizon. However, we find that both the 5 and $10 \mathrm{y}$ bond variance risk premia have strong predictive power for 5y bond returns and a similar pattern emerges as for the equity returns. While there is no predictive power for the shortest horizon, estimated coefficients are highly significant 
starting at a horizon of three months. Estimated coefficients increase both for the 5 as well as the $10 \mathrm{y}$ variance risk premium. However, for the $30 \mathrm{y}$ variance risk premium we find no predictive power except for the one year horizon, for which the $t$-statistic is -2.19 .

Panel $\mathrm{C}$ mirrors the findings of panel $\mathrm{b}$ for the $10 \mathrm{y}$ bond returns. Again, we find that both the 5 and 10y bond variance risk premia have strong predictive power which increases with the horizon. The 30y bond variance risk premium, on the other hand, is not statistically significant. Finally, for the 30y bond returns (presented in panel D), we find that only 5y variance risk premium has significant predictive power for bond returns between 3 and 12-months while the $\operatorname{TVRP}(10)$ contains some power but only at 12-months.

\section{[ Insert Figure 8]}

We present longer horizon $t$-statistics and $R^{2}$ for the bond returns in Figure 8. We note that both the 5 and 10y bond VRP have the strongest predictive power at the one year horizons as we observe an U-shaped pattern for the $t$-statistics: They increase with the horizon and then start to decrease again. For the $30 \mathrm{y}$ bond returns, the strongest predictive power is at around 20 months but the it reverts back again.

\section{B. Multivariate Regressions}

We now want to study whether equity and bond variance risk premia can jointly predict equity and bond excess returns. To this end, we run a regression from the equity excess returns onto the equity and bond variance risk premium jointly. Since the different variance risk premia across tenors are highly correlated, we only include one bond variance risk premium at a time.

Panel A of Table IV reports the results. We find that the equity variance risk premium remains a highly statistical significant predictor even when adding the bond variance risk premia. As in the univariate results, neither the 5- nor 10-year bond variance risk premia have predictive power for equity returns. However, the $30 \mathrm{y}$ bond variance risk premium is highly statistically significant for horizons six and twelve months. Interestingly, we find that the 30y bond variance risk premium drives out the predictive power of the equity variance risk premium at the annual horizons. This result is important since it suggests long term bond variance risk premia and equity variance risk premia capture different dimensions of compensation for asset return variance.

In Panels B to D, we focus on a set of bivariate regressions where we add the equity VRP as a second predictor variable to either the $5 \mathrm{y}, 10 \mathrm{y}$, or $30 \mathrm{y}$ bond VRP:

$$
x r t_{t+h}^{(i)}=\alpha_{i, h}+\beta_{i, h} T V R P_{t}^{(i)}+\beta_{E V R P, h} E V R P_{t}+\epsilon_{t+h}^{(i)}
$$

where $E V R P_{t}$ denotes the equity VRP and $T V R P^{(i)}$ stands for the respective bond VRP. 
The results from the univariate regressions mostly carry over to the bivariate case: 5y TVRP and 10y TVRP have strong predictive power for horizons above one month whereas neither the 30y nor the equity VRP are significant. In summary, the TVRP retain their predictive power when paired in a horse race with the equity VRP. At the same time, the 30y TVRP drives out the equity VRP as a predictor of stock excess returns.

\section{Controls}

We now study the extent to which the predictive ability of variance risk premia is related to alternative forecasting factors studied by the literature. In the context of equity predictability we consider the the log dividend yield (DY), the log earnings to price ratio (EP), and the net equity expansion (NTIS) from Goyal and Welch (2008). In the context of bond return predictability we consider the slope (Slope) as in Fama and Bliss (1987), the forward rate factor (CP) first studied by Cochrane and Piazzesi (2005), and two macro factors extracted from a large panel macro growth rates as in Ludvigson and $\mathrm{Ng}$ (2009). Table V reports estimates for equity and table VI reports results bonds. Top panels in each table report findings for 6-month holding periods and bottom panels report findings for 12-month holding periods.

\section{[ Insert Tables $\mathrm{V}$ to $\mathrm{VI}]$}

We noted above when discussing table IV that TVRP(30) predictability is capturing a different dimension of risk than equity VRP and TVRP(30) predictability resembles DY predictability in terms of the pattern in long horizons $R^{2}$ 's. Indeed, comparing the equity predictability columns of table IV] column 4 of table $\mathrm{V}$ we see the price dividend ratio is driving out $T V R P(30)$. This result suggests part of the variability in the price dividend ratio that pertains to discount rates is coming is coming from compensation for volatility risk. Volatility risk compensation that is showing up in long term bonds but is largely orthogonal to equity variance risk premia itself. Finally, we note $\operatorname{TVRP}(30)$ predictability is robust to the EP and NTIS factors.

Consider 10 Year Treasury futures returns we find that TVRP(10) predictability is not related to conditional first moments of macro (LN1 and LN2) however TVRP(10) predictability is correlated with Slope and CP predictability. In fact slope and CP are driving out TVRP predictability which implies part of the variability in the slope and CP factors that is related to volatility risk is due to volatility risk compensation. This result is interesting in the context of the seminal findings by Duffee (2002) that the slope does not proxy for volatility which spawned a vast literature developing term structure models with flexible price of risk specifications.

Our findings show that while the slope does not proxy volatility itself, it does proxy for volatility risk compensation. This finding also relates to a recent literature that studies the spanning properties of bond yields (Joslin, Priebsch, and Singleton (2014) and Duffee (2011)). 
This literature shows that many factors useful in understanding future yields and not contained in the yield curve today, a property that is difficult to reconcile within standard structural settings. Our findings on Treasury variance risk premia are, in fact, the intuitive result: the underlying state variables driving variance risk premia are also common to date $t$ yields. The final rows of table VI make this point clear in a two stage regression. First, we project TVRP $(10)$ on Slope and CP factors

$$
\begin{aligned}
& T V R P_{t}(10)=\alpha+\underbrace{(-0.49)}_{-4.48} \text { Slope }_{t}+\text { error }_{t}^{\text {Slope }}, \quad R^{2}=24 \% \\
& T V R P_{t}(10)=\alpha+\underbrace{(-0.31)}_{-3.19} C P_{t}+\text { error }_{t}^{\mathrm{CP}} \quad, \quad R^{2}=10 \%
\end{aligned}
$$

and take the fitted value as that component spanned by the slope / CP and uncorrelated residual component. The final specification considers this decomposition and shows that the component of Treasury variance risk which is forecasting expected excess bond returns is indeed in the date $t$ information set common to yields.

\section{Real and Nominal Risks}

In this section we propose a simple approach to study the link between variance risk premia and real versus nominal risks. As is common in the literature, we assume the expected growth rate in consumer prices (inflation) follows an $\mathrm{AR}(1)$ process ${ }^{11}$ Next, we exploit survey forecasts of inflation from BlueChip Financial Forecasts (BCFF) to estimate the inflation process. Solving the diffusion provides the one-step ahead inflation process and a parametric model for the survey forecasts

$$
\begin{aligned}
& \underbrace{\pi_{t+1}}_{X_{t+1}}=\theta_{\pi}\left(1-e^{-\kappa_{\pi}}\right)+\underbrace{e^{-\kappa_{\pi}}}_{F} \underbrace{\pi_{t}}_{X_{t}}+\varepsilon_{t+1} \\
& \underbrace{E\left[\pi_{\tau}\right]}_{Y(\tau)}=\underbrace{\theta_{\pi}\left(1-e^{-\kappa_{\pi} \tau}\right)}_{A(\tau)}+\underbrace{e^{-\kappa_{\pi} \tau}}_{H(\tau)} \underbrace{\pi_{t}}_{X_{t}}+\nu_{\tau}
\end{aligned}
$$

where $\varepsilon_{t+1}$ is a shock to expected inflation and $\nu_{\tau}$ is a forecast horizon independent measurement error. Survey forecasts can then be viewed as arising from a discrete time state space setting with measurement equations $Y(\tau)=A(\tau)+H(\tau) X_{t}+\nu_{t}$ and transition equation $X_{t+1}=$ $C+F X_{t}+\varepsilon_{t+1}$. We obtain the parameters of this system and the hidden state $\left(X_{t}\right)$ by maximum likelihood via the Kalman filter. The parameter estimates of the model imply expected inflation

\footnotetext{
${ }^{11}$ We model inflation as a continuous time $\operatorname{AR}(1)$ process (Ornstein-Uhlenbeck) and solve the transition density forward for arbitrary horizons.
} 
is a low volatility process with a mean of $3 \%$ and a half life 1.77 years ${ }^{12}$ The left panel of Figure 9 plots the one to four quarters ahead inflation forecasts from BCFF. The red line displays the filtered inflation state which displays the well documented downward trend over time. The right panel of Figure 9 plots inflation risk premia estimates computed as the difference between break-even rates and model implied inflation forecasts. The time series show that inflation risk premia are on average negative for the period where TIPS yields are available. Moreover, they remain relatively flat across maturities, and display a large deflationary spike at the on-set of the financial crisis that takes some time to rebound. This seems to make intuitive sense if one considers that (physical) inflation expectations have remained relatively stable through the crisis period whereas break-even inflation has dropped considerably. 13

\section{[ Insert Figure 9]}

Standard textbook algebra tells us that break-even inflation is equal to expected inflation plus the inflation risk premium: $I R P_{t, \tau}=Y_{t, \tau}^{\$}-Y_{t, \tau}-E_{t}\left[\pi_{\tau}\right]$. In the following we focus on 2-year inflation risk premia to match the four quarter maximum forecast horizon we use in constructing expected inflation.

Table VII reports contemporaneous OLS estimates from projecting variance risk premia (VRP), stock-bond correlations (SB Corr), and variance risk premia correlations (VRP Corr) on the first two principal components of the nominal term structure and the 2-year inflation risk premium (IRP) ${ }^{14}$ The sample period is January 2000 to December 2013 and the frequency is monthly for all regressions.

Considering Treasury variance risk premia, we obtain $R^{2}$ 's of $48 \%$ and $44 \%$ for $T V R P^{10}$ and $T V R P^{30}$, respectively. This implies that a significant degree of variation in compensation for variance risk is spanned by the nominal term structure. The level of the term structure has a positive and highly significant loading on $T V R P^{30}$, with a point estimate of 0.37 and t-statistic of 4.05. Remembering that TVRP are negative on average, this implies that negative shocks to short term interest rates, such as rate cuts by the Federal Reserve, raise (in absolute terms) the compensation required for holding volatility risk on long term bonds. The slope of the term

\footnotetext{
${ }^{12}$ The point estimates are given by $\theta=3.00, \kappa=0.38$, and $\sigma=0.81$.

${ }^{13}$ Inflation risk premia cannot be measured in a straightforward and unambiguous way for a long sample period. As such, any estimates are inherently model dependent. Our simple approach seems to capture the salient facts that inflation risk premia have been very small if not negative for the last decade and that break-even inflation has collapsed during the financial crisis (see, for example, Chernov and Mueller (2012) or Haubrich, Pennacchi, and Ritchken (2012)).

${ }^{14}$ To keep the results manageable, we drop the 5-year Treasury variance risk premium. The results for this tenor are the same as for the 10-year tenor and are available on request. Principal components of yields are computed using maturities between two and ten years (to remain consistent between nominal and real yields, where no short-term rates are available). The slope (or second PC) is rotated such that a positive shock to this factor raises long term yields and lowers short term yields. T-statistics are reported in parentheses and computed using Newey and West (1987) standard errors with twelve lags. Left and right hand variables are standardized.
} 
structure loads with a significant negative coefficient on $T V R P^{10}$. This is interesting positive shocks to the slope of the yield curve are often interpreted as a signal of increased risk through a term premium component. Our results show that this interpretation lines up with an increase in compensation for Treasury variance risk. Considering equity variance risk premia, we find no relationship to the level of yields but a significant loading on the slope of the term structure, with a point estimate of -0.29 and t-statistic of -3.64 . The final rows report estimates for our proxy for IRP. The results are striking. For both stock and bond variance risk premia IRP load positively with point estimates significant at the $1 \%$ level. In economic terms the impact of IRP of TVRP/EVRP is large. For example, a 1-standard deviation negative shock to IRP raises $T V R P^{10}$ by 0.72 standard deviations and EVRP by 0.61 standard deviations. We take up the interpretation of this finding below.

Next, considering stock-bond correlations we find a positive relationship to the level of the term structure. This finding is somewhat stronger but consistent with the empirical evidence presented by Hasseltoft (2009) and David and Veronesi (2015). Their theoretical interpretation is that the level of yields, a proxy for expected inflation, plays a negative signalling role for future economic growth in inflationary environments (i.e., pre-2000) and a positive signalling role in deflationary environments (i.e., post-2000). The net result is a positive link between stock-bond correlation and the level of yields via a cash flow channel. However, controlling for the level, we find an equally strong link to inflation risk premia. At the same time, the final columns of VII show a strong negative relationship between variance risk premia correlations. Taken together, deflation shocks (negative inflation shocks) drive a common demand for volatility risk compensation but drive a wedge between return correlations in the underlying. Table VIII checks the robustness of these findings by repeating the regressions with the the level and slope of real yields (TIPS) and our proxy for inflation risk premia. This table shows our findings are robust to spanning real-nominal risks using either nominal yields and IRP or real yields and IRP. The message is the same. Finally, one might be concerned that this finding is driven by a few data points during the financial crisis. Indeed, both variance risk premia and deflation risk premia reached record levels in period. However, in an online appendix we re-run the regressions in tables VII and VIII excluding the period from 2008 onwards and confirm that our findings are robust.

$$
\text { [ Insert Tables VII and VIII here ] }
$$

\section{Discussion}

The correlation between stock and bond returns varies substantially over time. Between the early 1960s and mid 1990s stock-bond correlation was positive and so bonds were considered 
risky. Figure 4 shows that around the LTCM crisis stock-bond correlation flipped sign and became negative. After the dot-com bubble burst, stock-bond correlation first hovered around zero and then turned very negative during the financial crisis. It has remained so ever since; thus, bonds now command a negative risk premium and are considered hedges.

Motivated by an empirical literature on inflation non-neutrality a stream of the literature has tried to understand this phenomenon in terms of inflation shocks and real shocks. For example, Piazzesi and Schneider (2007) assume that investors dislike shocks to inflation for two reasons: $(i)$ it lowers the payoff on nominal bonds; and $(i i)$ it is bad news for future consumption growth. The second effect can be large when investors have recursive utility with preference for early resolution of uncertainty à la Bansal and Yaron (2004). Hasseltoft (2009) considers the impact of this setting for dividend growth and studies the joint properties of the 'Fed Model' and the stock-bond covariance ${ }^{15}$ Campbell, Sunderam, and Viceira (2016) study real-nominal covariance in the context of a latent factor quadratic term structure model. In the context of a New Keynesian framework Campbell, Pflueger, and Viceira (2014) argue that monetary policy shifts in reaction to supply versus demand shocks alter the relationship between stocks and bond in way that can also rationalise these findings.

At the same time, a large but separate literature has devoted attention to studying variance risk premia. In reduced form, Carr and Wu (2009), Martin (2013), and Bondarenko (2014) use different approaches to reach the common conclusion that equity variance risk premia are large, negative and displays substantial time-variation, especially in periods of distress, financial and economy uncertainty. A smaller but growing literature studies Treasury variance risk premia. Trolle (2009) reports that shorting variance swaps in the Treasury futures market generates Sharpe ratios that three times larger than the Sharpe ratios of the underlying Treasury futures. Choi, Mueller, and Vedolin (2016) empirically document large and negative Treasury variance risk premia and argue that there are significant returns to variance trading in Treasury markets that are comparable to the equity variance market. In the context of equity variance risk premia, Bollerslev, Tauchen, and Zhou (2009), Zhou and Zhu (2009), and Bollerslev, Sizova, and Tauchen (2012) each study economies with long run risks and recursive preferences. When preferences are time-non-separable volatility risk is priced and gives rise to a natural structural understanding of variance risk premia.

Surprisingly, little attempt have been made to link these literatures. Our findings provide evidence that these literatures are, in fact, linked by a common denominator: the inflation risk premium.

The intuition for the result is straightforward. After the Russian Crisis and LTCM, the relationship between stocks and bonds changes. From a CAPM perspective, bonds are now

\footnotetext{
${ }^{15}$ The Fed Model is an often used term to describe the positive relation between U.S. dividend yields and nominal interest rates.
} 
considered hedges and command a negative term premium. In this state of the world, when the volatility of inflation increases the term premia on bonds becomes even more negative because of deflationary risks. This naturally links to compensation for volatility risks since stock and bond markets are also exposed to shocks to the volatility of inflation. At the same time, negative shocks to IRP (or positive shocks to inflation volatility) drive up bond yields and down their prices. Stocks, however, remain risky so their prices also go down with these shocks and the net effect is a positive link to the stock-bond correlation. Finally, and intuitively, shocks to IRP are positively correlated with demand to hedge volatility risks because these shocks are also common to the underlying assets.

\section{Conclusion}

We document a set of novel facts about variance risk premia on stock and bonds.

First, the premium that investors are willing to pay to hedge against changes in expected bond variance is smaller in absolute terms than the equity variance risk premium. However, accounting for the volatility of VRP, we document that the economic magnitude of variance risk premia on bonds is as large as that on stocks. Understanding these magnitudes poses an interesting challenge for future asset pricing models.

Second, the correlation between stock and bond VRP is unconditionally positive $(\sim 20 \%)$ but conditionally displays high frequency variation ranging between $0 \%$ and $60 \%$ and has been especially volatile since the financial crisis. These dynamics are distinct from the well studied pattern of stock-bond return correlation thus lending a novel channel through which to learn about pricing of volatility risk.

Third, both equity and bond variance risk premia predict equity and bond excess returns at both short horizons (3-months) and long horizons (12-months): ( $i$ ) short maturity TVRP predicts excess returns on short maturity bonds; (ii) long maturity TVRP and EVRP predict excess returns on long maturity bonds; and (iii) while EVRP predicts equity returns for horizons up to 6-months, long maturity TVRP is a formidable predictor at longer horizons.

Finally, we investigate the economic determinants of variance risk premia, stock-bond correlation, and the co-movement between variance risk premia. Using regression based evidence on nominal Treasuries, real Treasuries and survey data we document that deflation risk premia are a powerful common factor across stock and bond markets. We leave a full structural interpretation for future research. 


\section{References}

Adrian, Tobias, Richard Crump, and Erik Vogt, 2016, Nonlinearity and flight to safety in the risk-return trade-off for stocks and bonds., FRB of New York Working Paper.

Allen, Peter, Stephen Einchcomb, and Nicolas Granger, 2006, Variance swaps, JP Morgan Investment Strategies No. 28.

Andersen, Torben G., Tim G. Bollerslev, and Francis X. Diebold, 2007, Roughing it up: Including jump components in the measurement, modeling, and forecasting of return volatility, The Review of Economics and Statistics 89, 701-720.

Asgharian, Hossein, Charlotte Christiansen, and Ai Jun Hou, 2016, Macro-finance determinants of the long-run stockbond correlation: The dcc-midas specification, Journal of Financial Econometrics 14, 617-642.

Baele, Lieven, Geert Bekaert, and Koen Inghelbrecht, 2010, The determinants of stock and bond return comovements, Review of Financial Studies 23, 2374-2428.

Bansal, Ravi, and Amir Yaron, 2004, Risks for the long run: A potential resolution of asset pricing puzzles, Journal of Finance 59, 1481-1509.

Barras, Laurent, and Aytek Malkhozov, 2016, Does variance risk have two prices? evidence from the equity and option markets, Journal of Financial Economics 121, 79-92.

Bekaert, Geert, and Marie Hoerova, 2014, The VIX, the variance premium and stock market volatility, Journal of Econometrics 183, 181-192.

Bollerslev, Tim, Natalia Sizova, and George Tauchen, 2012, Risks for the long run: A potential resolution of asset pricing puzzles, Review of Finance 16(1), 31-80.

Bollerslev, Tim G., George Tauchen, and Hao Zhou, 2009, Expected stock returns and variance risk premia, Review of Financial Studies 22, 4463-4492.

Bondarenko, Oleg, 2014, Variance trading and market price of variance risk, Journal of Econometrics 180, 81-97.

Busch, Thomas, Bent Jesper Christensen, and Morten Ørregaard Nielsen, 2011, The role of implied volatility in forecasting future realized volatility and jumps in foreign exchange, stock, and bond markets, Journal of Econometrics 160, 48-57.

Campbell, John Y, Carolin Pflueger, and Luis M Viceira, 2014, Monetary policy drivers of bond and equity risks, Discussion paper, National Bureau of Economic Research.

Campbell, John Y., Adi Sunderam, and Luis M. Viceira, 2016, Inflation bets or deflation hedges? the changing risks of nominal bonds, Working Paper, Harvard Business School.

Carr, Peter, and Liuren Wu, 2009, Variance risk premiums, Review of Financial Studies 22, 1311-1341.

Chernov, Mikhail, and Philippe Mueller, 2012, The term structure of inflation expectations, Journal of Financial Economics 106, 367-394. 
Choi, Hoyong, Philippe Mueller, and Andrea Vedolin, 2016, Bond variance risk premiums, forthcoming, Review of Finance.

Cochrane, John H., and Monika Piazzesi, 2005, Bond risk premia, American Economic Review 95, 138-160.

Corsi, Fulvio, 2009, A simple approximate long-memory model of realized volatility, Journal of Financial Econometrics 7, 174-196.

— David Pirino, and Roberto Renò, 2010, Threshold bipower variation and the impact of jumps on volatility forecasting, Journal of Econometrics 159, 276-288.

David, Alexander, and Pietro Veronesi, 2015, The economics of the comovement of stocks and bonds, Handbook of Fixed Income. John Wiley Eamp; Sons.

Dew-Becker, Ian, Stefano Giglio, Anh Le, and Marius Rodriguez, 2016, The price of variance risk, forthcoming, Journal of Financial Economics.

Duffee, Gregory R., 2002, Term premia and interest rate forecasts in affine models, Journal of Finance 57, 405-443.

, 2011, Information in (and not in) the term structure, Review of Financial Studies 24, $2895-2934$.

Fama, Eugene F., and Robert R. Bliss, 1987, The information in long-maturity forward rates, American Economic Review 77, 680-692.

Ghysels, Eric, Pierre Guérin, and Massimiliano Marcellino, 2014, Regime switches in the riskreturn trade-off, Journal of Empirical Finance 28, 118-138.

Goyal, Amit, and Ivo Welch, 2008, A comprehensive look at the empirical performance of equity premium prediction, Review of Financial Studies 21, 1455-1508.

Hasseltoft, Henrik, 2009, The'fed model'and the changing correlation of stock and bond returns: An equilibrium approach, Available at SSRN 1361489.

Haubrich, Joseph, George Pennacchi, and Peter Ritchken, 2012, Inflation expectations, real rates, and risk premia: Evidence from inflation swaps, Review of Financial Studies 25, 15881629.

Joslin, Scott, Marcel Priebsch, and Kenneth J. Singleton, 2014, Risk premiums in dynamic term structure models with unspanned macro risks, forthcoming, Journal of Finance.

Li, Lingfeng, 2002, Macroeconomic factors and the correlation of stock and bond returns, Working Paper, Yale University No 02-46.

Ludvigson, Sidney C., and Serena Ng, 2009, Macro factors in bond risk premia, Review of Financial Studies 22, 5027-5067.

Martin, Ian, 2013, Simple variance swaps, Working Paper, London School of Economics. 
Newey, Whitney K, and Kenneth D. West, 1987, A simple, positive semi-definite, heteroskedasticity and autocorrelation consistent covariance matrix, Econometrica 55, 703-708.

Piazzesi, Monika, and Martin Schneider, 2007, Equilibrium yield curves, in NBER Macroeconomics Annual 2006, Volume 21 . pp. 389-472 (MIT Press).

Trolle, Anders B., 2009, The price of interest rate variance risk and optimal investments in interest rate derivatives, Working Paper, EPFL.

Zhou, Guofu, and Yingzi Zhu, 2009, A long-run risks model with long- and short-run volatilities: explaining predictability and volatility risk premium, Working Paper. 


\section{Appendix: Figures}
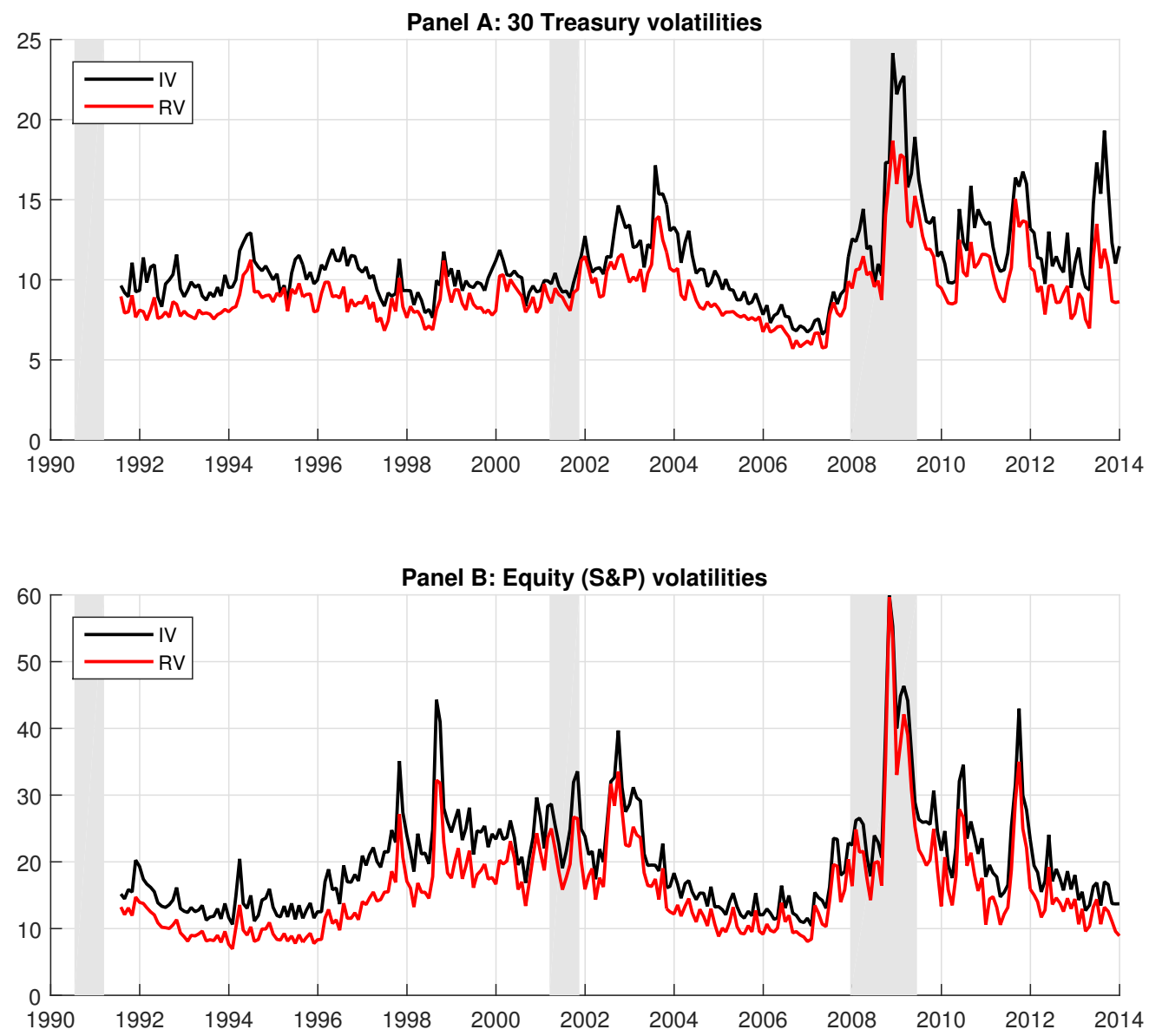

Figure 1. Expected Physical and Risk Neutral Volatility

Panel A plots the time series of the ex-ante physical and risk neutral 30-year Treasury volatility, while Panel B plots the same time series for the equity volatility. For the Treasury volatilities we use options on the Treasury futures as well as the underlying high-frequency price data. For the ex-ante riskneutral equity volatility we use the VIX index and to calculate the ex-ante physical volatility we use data on the S\&P 500 index. The calculation details of both measures are discussed in the main body of the paper. All series are annualized and expressed in percent. Data is monthly and runs from 1991 to 2014 . 



Figure 2. Equity and Treasury Variance Risk Premia

This figure plots the time series of Treasury and equity variance risk premia. Panel A compares Treasury variance risk premia on 5, 10, and 30-year Treasury futures and Panel B compares variance risk premia on 30-Treasury bond futures to the equity variance risk premia as measured by the S\&P 500 index. Variance risk premia are calculated as the difference between the ex-ante physical and risk neutral variances as discussed in the main body of the paper. The time series are in monthly terms and expressed in squared percent. Data is monthly and runs from 1991 to 2014. 


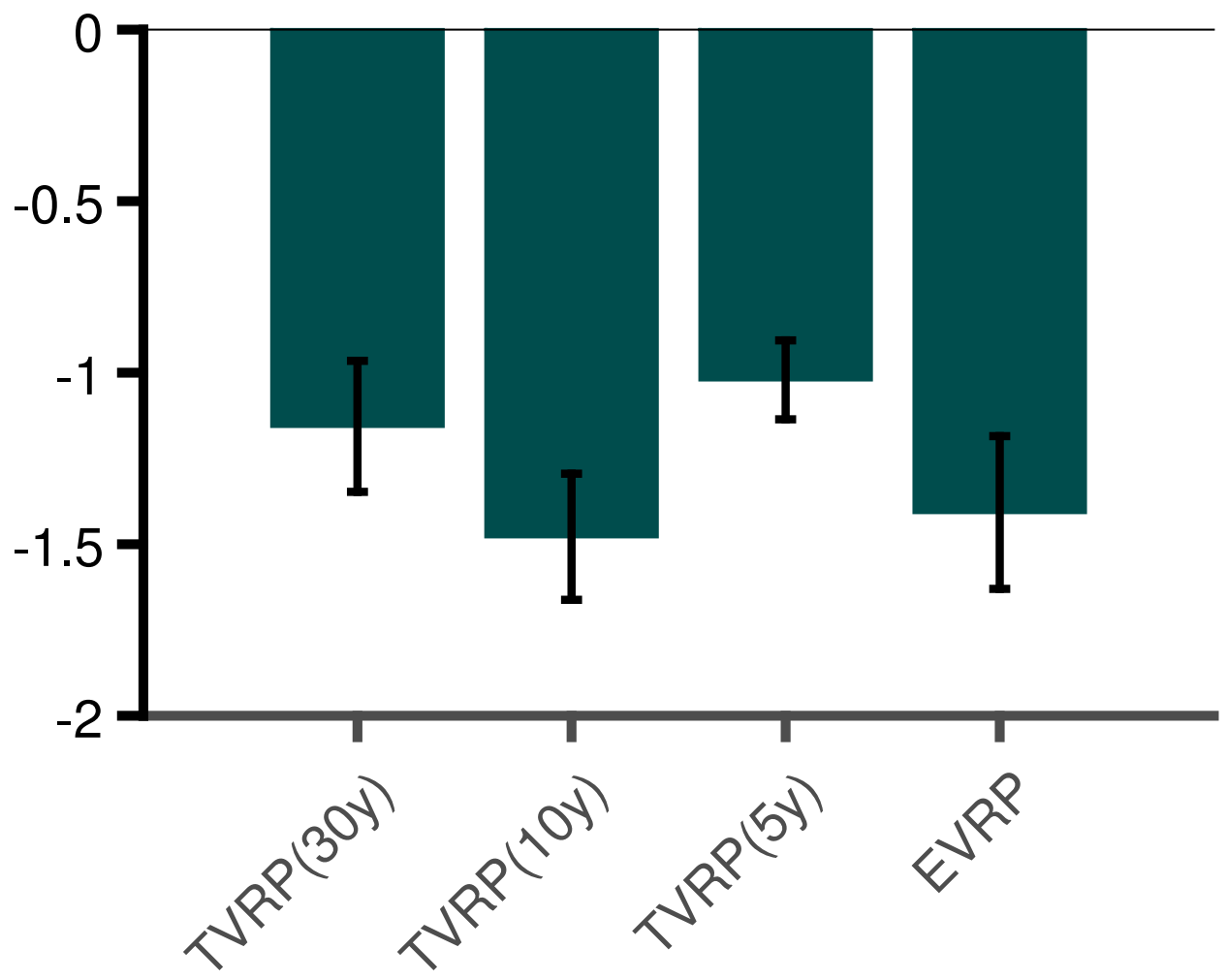

Figure 3. Standardised Variance Risk Premia

This figure plots the magnitude of variance risk premia on the S\&P 500 index as well as Treasuries relative to their volatility. Standard errors plotted in black are computed using a bootstrap procedure with 1000 repetitions. The data used to compute this plot runs from 1991 to 2014. 


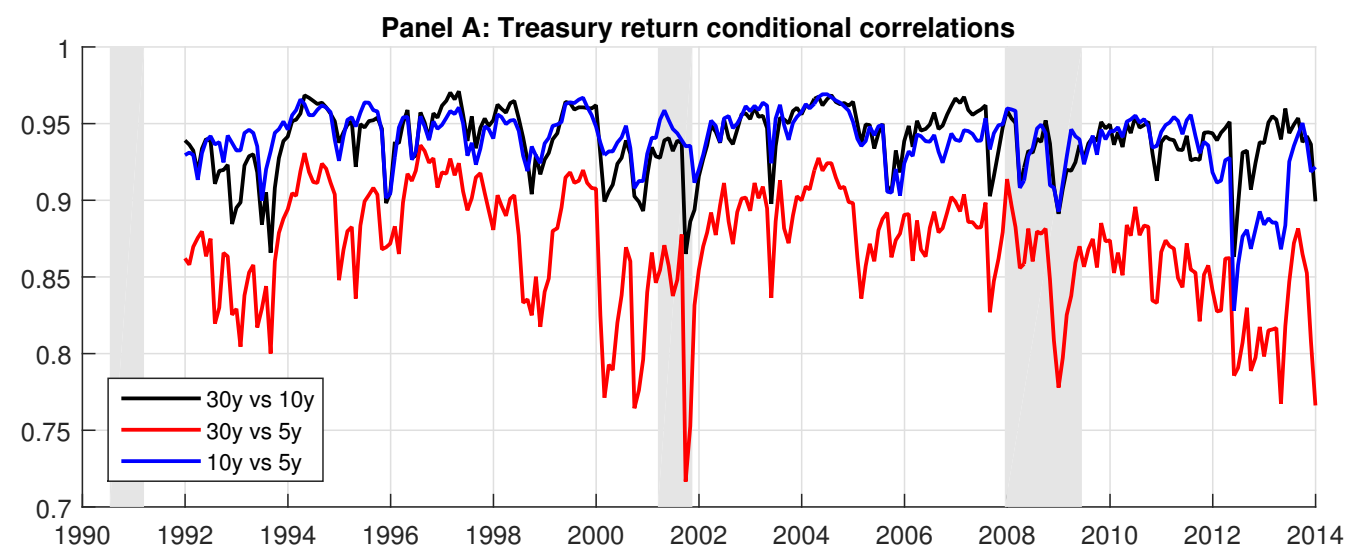

Panel B: Treasury and equity return conditional correlations

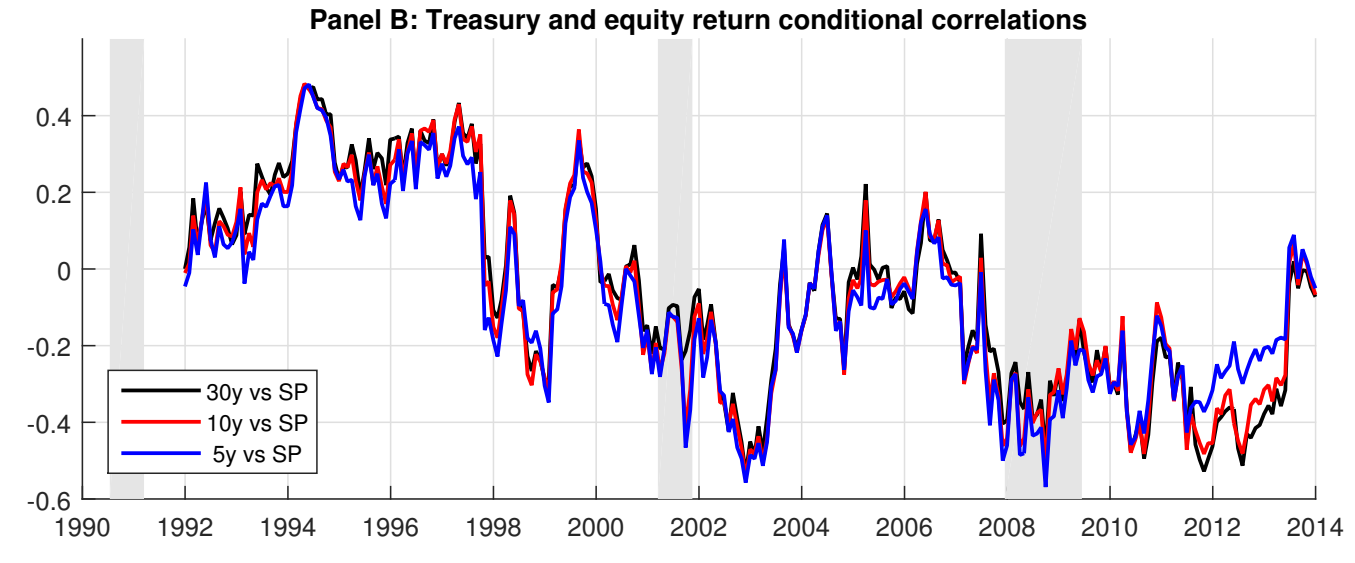

Figure 4. Conditional Correlations between Equity and Treasury Returns

Panel A plots the conditional correlations among daily Treasury futures returns (5-year, 10-year, and 30-year), while Panel B plots the conditional correlations between daily Treasury futures returns (5year, 10-year, and 30-year) and returns on the S\&P 500 futures. Conditional correlations are calculated by estimating a DCC model on daily data. The data is sampled at the monthly frequency and runs from 1991 to 2014 . 

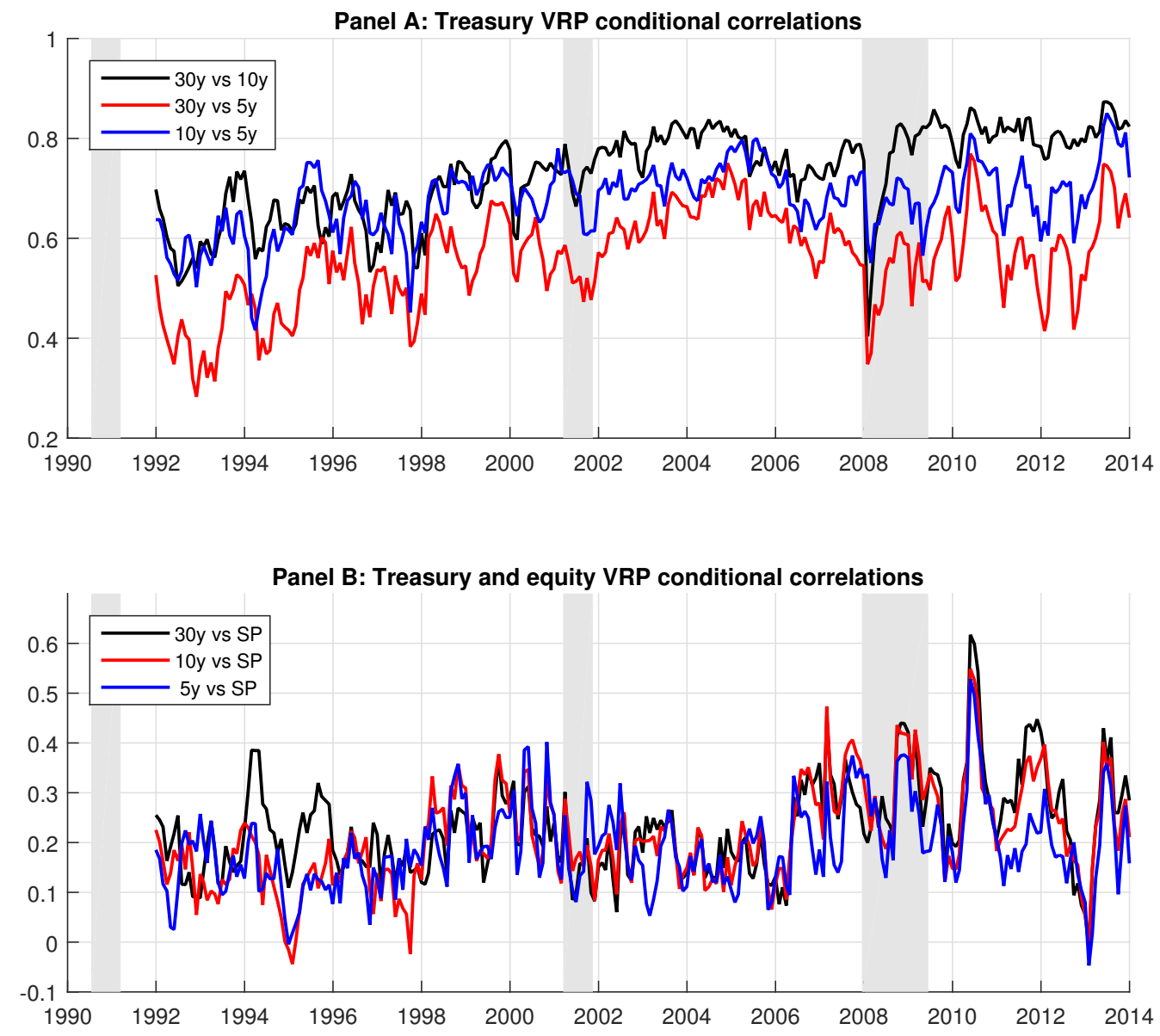

Figure 5. Conditional Correlations between Treasury and Equity Variance Risk Premia Panel A plots the conditional correlations among daily Treasury variance risk premia (5-year, 10-year, and 30-year), while Panel B plots the conditional correlations between daily Treasury variance risk premia (5-year, 10-year, and 30-year) and variance risk premia on the S\&P 500 index. Conditional correlations are calculated by estimating a DCC model on the residuals from a VAR using daily variance risk premia. The data is sampled at the monthly frequency and runs from 1991 to 2014. 

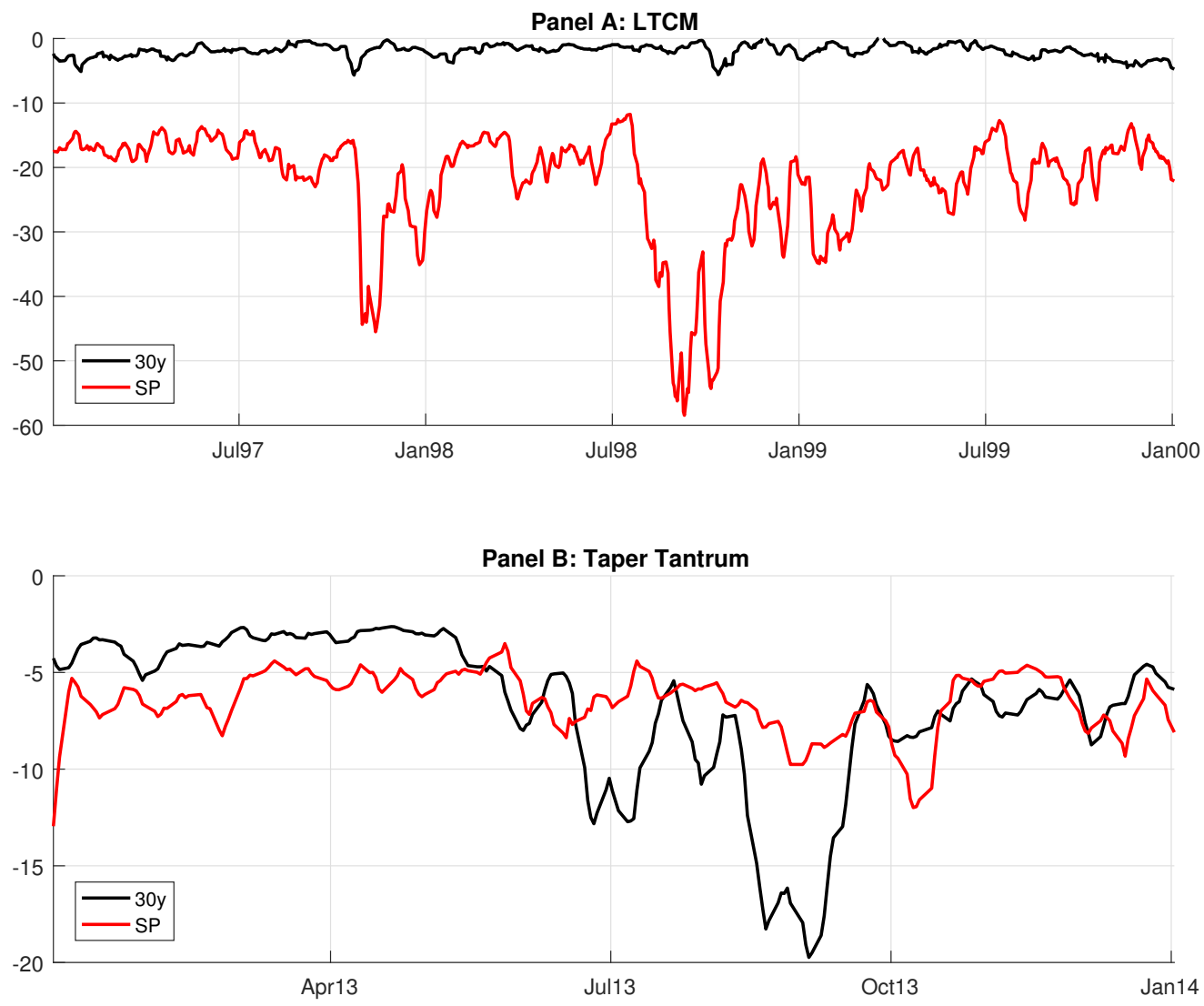

Figure 6. Variance Risk Premia around LTCM and Tamper Tantrum

Panel A plots the 30-year Treasury futures and equity variance risk premia between January 1997 and December 1999. Panel B plots the 30-year Treasury futures and equity variance risk premia between January 2013 and December 2013. Data is daily and the time series are slightly smoothed by taking five day rolling averages. 

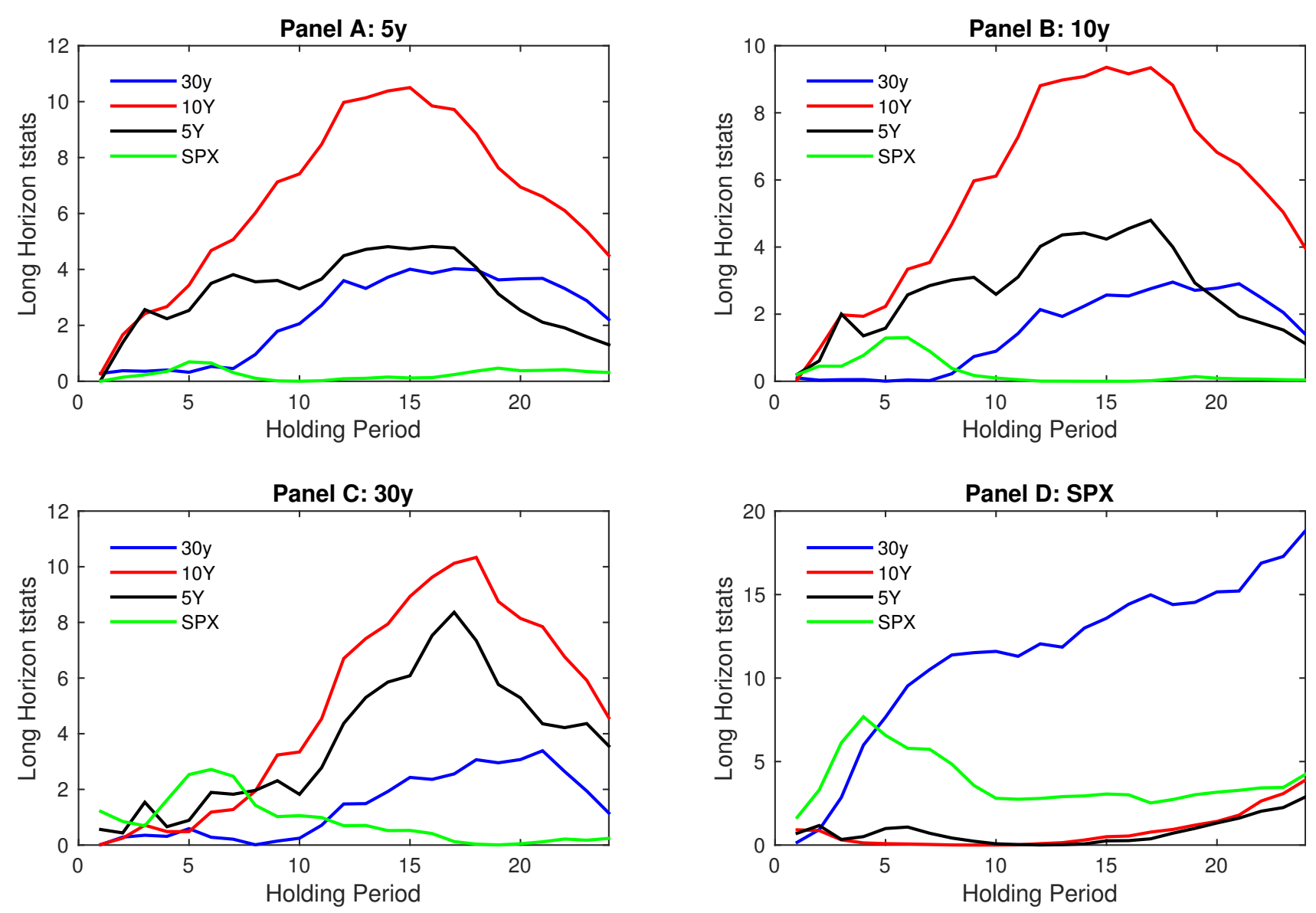

(a)

Figure 7. Futures Excess Returns Long Horizon Predictability

This figure plots $R^{2}$ obtained from the h-period univariate predictability regressions: $x r t_{t+h}^{j}=\alpha_{i, h}+$ $\beta_{i, h} V R P_{t}^{(i)}+\epsilon_{t+h}^{(i)}$, where $j$ is 5y, 10y, 30y, SPX, respectively. The sample period is 1991 to 2014 for all regressions. Left and right hand variables are standardised. 

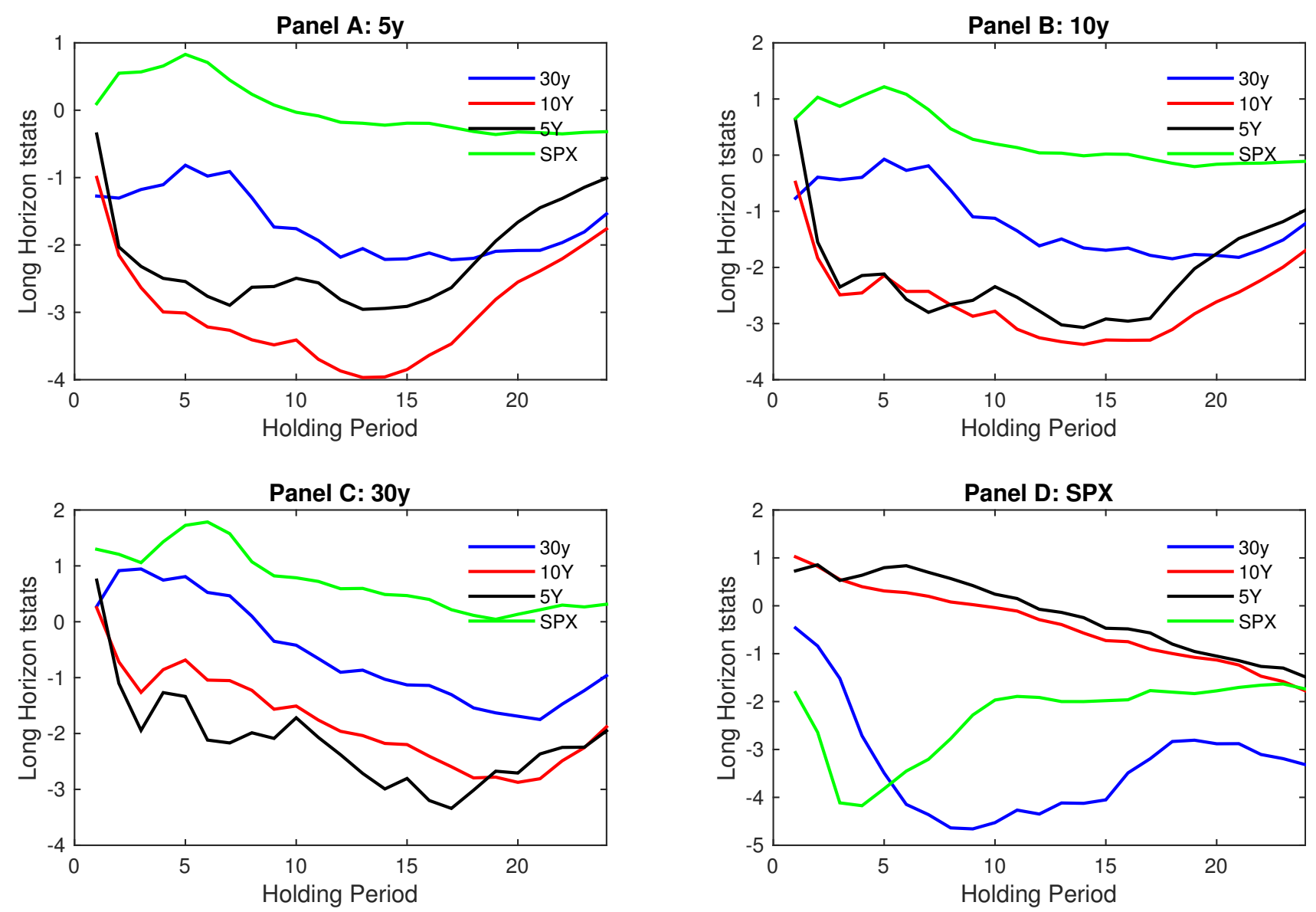

(a)

Figure 8. Futures Excess Returns Long Horizon Predictability

This figure plots t-statistics obtained from the h-period univariate predictability regressions: $x r t_{t+h}^{j}=$ $\alpha_{i, h}+\beta_{i, h} V R P_{t}^{(i)}+\epsilon_{t+h}^{(i)}$, where $j$ is $5 \mathrm{y}, 10 \mathrm{y}, 30 \mathrm{y}$, SPX, respectively. The sample period is 1991 to 2014 for all regressions. Left and right hand variables are standardised. 

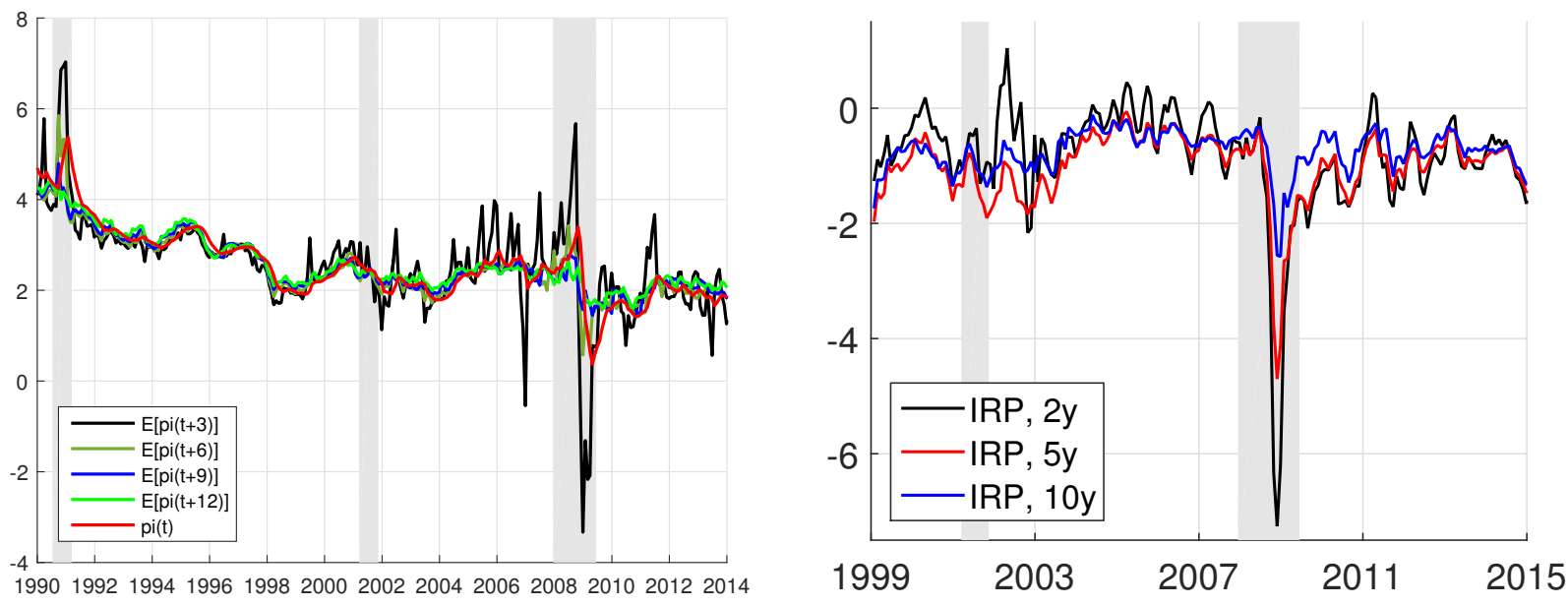

Figure 9. Inflation Forecast

The left panel plots survey forecasts of inflation for one through four quarters ahead from BlueChip Financial Forecasts (BCFF). The red line displays the instantaneous hidden state filtered from the cross section of forecasts. The top right panel displays model implied inflation risk premia on 2,5, and 10-year bonds computed as the difference between break-even inflation rates and expected inflation implied by the estimated state-space estimates: $E\left[\pi_{\tau}\right]=\theta_{\pi}\left(1-e^{-\kappa_{\pi} \tau}\right)+e^{-\kappa_{\pi} \tau} \pi_{t}$ where $\theta=3.00, \kappa=0.38$, and $\sigma=0.81$. 


\section{Appendix: Tables}

\begin{tabular}{lccccc}
\hline & 30y Bond & 10y Bond & 5y Bond & $\begin{array}{c}\text { S\&P 500 } \\
\text { futures }\end{array}$ & $\begin{array}{c}\text { S\&P 500 } \\
\text { index }\end{array}$ \\
\cline { 2 - 6 } Mean & 1.52 & 1.51 & 0.09 & 2.91 & 3.91 \\
Std Dev & 9.47 & 6.17 & 4.15 & 14.86 & 14.90 \\
Min & -10.62 & -6.05 & -3.42 & -19.07 & -18.64 \\
Max & 12.78 & 8.29 & 5.13 & 10.57 & 10.23 \\
Skew & -0.01 & 0.11 & 0.09 & -0.82 & -0.80 \\
Kurt & 5.29 & 4.43 & 3.93 & 4.86 & 4.71 \\
AR $(1)$ & 0.04 & 0.10 & 0.15 & 0.08 & 0.06 \\
\hline
\end{tabular}

Table I. Summary Statistics: Futures Excess Returns

The table reports summary statistics for 1-month returns in excess of the one-month Treasury Bill rate for 5-year, 10year, and 30-year Treasury bond futures and the S\&P 500 index futures. For comparison, we also report the one-month excess returns on the S\&P 500 index. Means and standard deviations are annualized and expressed in percent. Data is monthly and runs from July 1991 to December 2013. 


\begin{tabular}{|c|c|c|c|c|}
\hline & 30y Bond & 10y Bond & 5y Bond & $\begin{array}{c}\text { S\&P } 500 \\
\text { index }\end{array}$ \\
\hline \multicolumn{5}{|c|}{ Panel A: Physical Volatility } \\
\hline Mean & 9.28 & 5.95 & 4.01 & 15.84 \\
\hline Std Dev & 2.04 & 1.25 & 0.93 & 7.30 \\
\hline Min & 5.70 & 3.17 & 1.59 & 6.96 \\
\hline Max & 18.69 & 10.62 & 7.68 & 59.64 \\
\hline Skew & 1.59 & 0.96 & 0.32 & 2.10 \\
\hline Kurt & 6.85 & 5.09 & 3.95 & 10.25 \\
\hline $\operatorname{AR}(1)$ & 0.86 & 0.84 & 0.84 & 0.85 \\
\hline \multicolumn{5}{|c|}{ Panel B: Risk Neutral Volatility } \\
\hline Mean & 11.04 & 7.29 & 4.66 & 20.11 \\
\hline Std Dev & 2.69 & 1.70 & 1.29 & 7.85 \\
\hline Min & 6.60 & 3.97 & 1.79 & 10.42 \\
\hline Max & 24.15 & 14.33 & 9.69 & 59.89 \\
\hline Skew & 1.72 & 0.80 & 0.25 & 1.65 \\
\hline Kurt & 7.55 & 4.48 & 3.39 & 7.05 \\
\hline $\operatorname{AR}(1)$ & 0.85 & 0.84 & 0.83 & 0.86 \\
\hline \multicolumn{5}{|c|}{ Panel C: Variance Risk Premia } \\
\hline Mean & -3.24 & -1.59 & -0.54 & -13.48 \\
\hline Std Dev & 2.80 & 1.08 & 0.53 & 9.58 \\
\hline Min & -19.50 & -7.70 & -2.90 & -76.87 \\
\hline Max & -0.14 & 0.46 & 0.81 & -1.92 \\
\hline Skew & -2.97 & -1.60 & -1.20 & -2.31 \\
\hline Kurt & 15.27 & 7.95 & 5.29 & 11.89 \\
\hline $\operatorname{AR}(1)$ & 0.68 & 0.65 & 0.53 & 0.65 \\
\hline
\end{tabular}

Table II. Summary Statistics: Implied Volatilities and Variance Risk Premia

Panels A and B report summary statistics for one-month projected physical and risk neutral volatilities for 5-year, 10-year, and 30-year Treasury notes and bond futures and the S\&P 500 index, respectively. Panel $\mathrm{C}$ reports the corresponding statistics for the variance risk premia defined as the difference between realized and risk-neutral variances. Volatilities are annualized and expressed in percent. Variance risk premia are in monthly terms and expressed in squared percent. All series are sampled at the monthly frequency and data runs from July 1991 to December 2013. 


\begin{tabular}{|c|c|c|c|c|c|c|c|c|}
\hline h & $1 \mathrm{~m}$ & $3 \mathrm{~m}$ & $6 \mathrm{~m}$ & $12 \mathrm{~m}$ & $1 \mathrm{~m}$ & $3 \mathrm{~m}$ & $6 \mathrm{~m}$ & $12 \mathrm{~m}$ \\
\hline & \multicolumn{8}{|c|}{ Panel A: S\&P500 } \\
\hline & \multicolumn{4}{|c|}{ S\&P500 VRP } & \multicolumn{4}{|c|}{$5 y \mathrm{VRP}$} \\
\hline$\beta$ & -0.13 & -0.25 & -0.24 & -0.17 & 0.08 & 0.06 & 0.10 & -0.01 \\
\hline t-stat & $(-1.81)$ & $(-4.11)$ & $(-3.45)$ & $(-1.90)$ & $(0.73)$ & $(0.53)$ & $(0.84)$ & $(-0.06)$ \\
\hline \multirow[t]{2}{*}{$R^{2}$} & 1.66 & 6.12 & 5.79 & 2.76 & 0.71 & 0.33 & 1.08 & 0.00 \\
\hline & \multicolumn{4}{|c|}{$10 y$ VRP } & \multicolumn{4}{|c|}{$30 y$ VRP } \\
\hline$\beta$ & 0.10 & 0.06 & 0.03 & -0.03 & -0.04 & -0.17 & -0.31 & -0.35 \\
\hline t-stat & $(1.02)$ & $(0.55)$ & $(0.28)$ & $(-0.27)$ & $(-0.46)$ & $(-1.52)$ & $(-4.15)$ & $(-4.36)$ \\
\hline$R^{2}$ & 0.91 & 0.31 & 0.06 & 0.08 & 0.16 & 2.85 & 9.53 & 12.12 \\
\hline
\end{tabular}

Panel B: 5yr bond

\begin{tabular}{lcccccccc} 
& \multicolumn{9}{c}{ S\&P500 VRP } \\
\cline { 2 - 9 }$\beta$ & 0.01 & 0.05 & 0.08 & -0.03 & -0.02 & -0.16 & -0.19 & -0.21 \\
t-stat & $(0.10)$ & $(0.57)$ & $(0.71)$ & $(-0.17)$ & $(-0.35)$ & $(-2.32)$ & $(-2.76)$ & $(-2.77)$ \\
$R^{2}$ & 0.00 & 0.23 & 0.65 & 0.09 & 0.03 & 2.56 & 3.50 & 4.38 \\
& \multicolumn{9}{c}{$10 \mathrm{y}$ VRP } & & & $30 \mathrm{y} \mathrm{VRP}$ & \\
$\beta$ & -0.05 & -0.16 & -0.22 & -0.31 & -0.05 & -0.06 & -0.07 & -0.19 \\
t-stat & $(-1.00)$ & $(-2.63)$ & $(-3.22)$ & $(-3.85)$ & $(-1.27)$ & $(-1.18)$ & $(-0.98)$ & $(-2.19)$ \\
$R^{2}$ & 0.26 & 2.42 & 4.68 & 9.83 & 0.28 & 0.36 & 0.53 & 3.66
\end{tabular}

Panel C: 10yr bond

\begin{tabular}{lcccccccc} 
& \multicolumn{9}{c}{ S\&P500 VRP } \\
\cline { 2 - 9 }$\beta$ & 0.04 & 0.07 & 0.11 & 0.01 & 0.05 & -0.14 & -0.16 & -0.20 \\
t-stat & $(0.65)$ & $(0.87)$ & $(1.08)$ & $(0.05)$ & $(0.62)$ & $(-2.35)$ & $(-2.57)$ & $(-2.73)$ \\
$R^{2}$ & 0.20 & 0.45 & 1.30 & 0.01 & 0.21 & 2.00 & 2.58 & 3.88 \\
& \multicolumn{9}{c}{$10 \mathrm{y} \mathrm{VRP}$} & & \multicolumn{5}{c}{$30 \mathrm{y} \mathrm{VRP}$} \\
$\beta$ & -0.02 & -0.14 & -0.18 & -0.29 & -0.03 & -0.02 & -0.02 & -0.15 \\
t-stat & $(-0.48)$ & $(-2.49)$ & $(-2.43)$ & $(-3.24)$ & $(-0.77)$ & $(-0.44)$ & $(-0.27)$ & $(-1.63)$ \\
$R^{2}$ & 0.05 & 1.98 & 3.34 & 8.64 & 0.10 & 0.05 & 0.04 & 2.20
\end{tabular}

Panel D: 30yr bond

\begin{tabular}{lcccccccc} 
& \multicolumn{9}{c}{ S\&P500 VRP } \\
\cline { 2 - 9 }$\beta$ & 0.11 & 0.08 & 0.16 & 0.09 & 0.07 & -0.12 & -0.14 & -0.20 \\
t-stat & $(1.30)$ & $(1.06)$ & $(1.79)$ & $(0.61)$ & $(0.74)$ & $(-1.94)$ & $(-2.12)$ & $(-2.27)$ \\
$R^{2}$ & 1.21 & 0.69 & 2.72 & 0.74 & 0.56 & 1.54 & 1.89 & 4.02 \\
& \multicolumn{3}{c}{$10 \mathrm{y}$ VRP } & & \multicolumn{5}{c}{$30 \mathrm{y} \mathrm{VRP}$} \\
$\beta$ & 0.01 & -0.08 & -0.11 & -0.25 & 0.01 & 0.06 & 0.05 & -0.13 \\
t-stat & $(0.25)$ & $(-1.26)$ & $(-1.04)$ & $(-1.92)$ & $(0.27)$ & $(0.94)$ & $(0.52)$ & $(-0.93)$ \\
$R^{2}$ & 0.02 & 0.71 & 1.18 & 6.33 & 0.01 & 0.35 & 0.28 & 1.61 \\
\hline
\end{tabular}

Table III. Return Predictability Regressions (Univariate)

This table reports return predictability regressions of futures excess returns on the equity and treasury variance risk premia: $x r t_{t+h}^{(i)}=\alpha_{i, h}+\beta_{i, h} V R P_{t}^{(i)}+\epsilon_{t+h}^{(i)}$, where $h=1,3,6$ and 12 months. t-statistics are reported in parentheses and computed using Newey and West (1987) standard errors with twelve lags. The sample period is July 1991 to December 2013 for all regressions. Left and right hand variables are standardized. 


\begin{tabular}{|c|c|c|c|c|c|c|c|c|c|}
\hline & $3 \mathrm{~m}$ & $6 \mathrm{~m}$ & $12 \mathrm{~m}$ & $3 \mathrm{~m}$ & $6 \mathrm{~m}$ & $12 \mathrm{~m}$ & $3 \mathrm{~m}$ & $6 \mathrm{~m}$ & $12 \mathrm{~m}$ \\
\hline & \multicolumn{9}{|c|}{ Panel A: S\&P500 } \\
\hline$V R P^{S P X}$ & $\begin{array}{c}-0.27 \\
(-4.42)\end{array}$ & $\begin{array}{c}-0.27 \\
(-3.24)\end{array}$ & $\begin{array}{c}-0.17 \\
(-1.92)\end{array}$ & $\begin{array}{c}-0.28 \\
(-4.38)\end{array}$ & $\begin{array}{c}-0.26 \\
(-3.45)\end{array}$ & $\begin{array}{c}-0.17 \\
(-2.12)\end{array}$ & $\begin{array}{c}-0.22 \\
(-3.34)\end{array}$ & $\begin{array}{c}-0.17 \\
(-2.35)\end{array}$ & $\begin{array}{c}-0.08 \\
(-0.91)\end{array}$ \\
\hline$V R P^{5 y}$ & $\begin{array}{c}0.10 \\
(0.82)\end{array}$ & $\begin{array}{c}0.15 \\
(1.06)\end{array}$ & $\begin{array}{c}0.02 \\
(0.21)\end{array}$ & & & & & & \\
\hline$V R P^{10 y}$ & & & & $\begin{array}{c}0.12 \\
(0.95)\end{array}$ & $\begin{array}{c}0.09 \\
(0.85)\end{array}$ & $\begin{array}{c}0.01 \\
(0.14)\end{array}$ & & & \\
\hline$V R P^{30 y}$ & & & & & & & $\begin{array}{c}-0.11 \\
(-0.87)\end{array}$ & $\begin{array}{c}-0.26 \\
(-3.29)\end{array}$ & $\begin{array}{c}-0.33 \\
(-3.65)\end{array}$ \\
\hline \multirow[t]{2}{*}{$\bar{R}^{2}$} & 6.83 & 7.64 & 2.45 & 7.16 & 6.17 & 2.41 & 6.89 & 11.85 & 12.35 \\
\hline & \multicolumn{9}{|c|}{ Panel B: 5yr bond } \\
\hline$V R P^{S P X}$ & $\begin{array}{c}0.08 \\
(0.95)\end{array}$ & $\begin{array}{c}0.12 \\
(1.09)\end{array}$ & $\begin{array}{c}0.01 \\
(0.05)\end{array}$ & $\begin{array}{c}0.09 \\
(1.09)\end{array}$ & $\begin{array}{c}0.14 \\
(1.37)\end{array}$ & $\begin{array}{c}0.05 \\
(0.32)\end{array}$ & $\begin{array}{c}0.07 \\
(0.84)\end{array}$ & $\begin{array}{c}0.11 \\
(0.97)\end{array}$ & $\begin{array}{c}0.02 \\
(0.15)\end{array}$ \\
\hline$V R P^{5 y}$ & $\begin{array}{c}-0.17 \\
(-2.32)\end{array}$ & $\begin{array}{c}-0.21 \\
(-2.67)\end{array}$ & $\begin{array}{c}-0.21 \\
(-2.49)\end{array}$ & & & & & & \\
\hline$V R P^{10 y}$ & & & & $\begin{array}{c}-0.18 \\
(-2.65)\end{array}$ & $\begin{array}{c}-0.25 \\
(-3.42)\end{array}$ & $\begin{array}{c}-0.32 \\
(-3.57)\end{array}$ & & & \\
\hline$V R P^{30 y}$ & & & & & & & $\begin{array}{c}-0.08 \\
(-1.59)\end{array}$ & $\begin{array}{l}-0.10 \\
(-1.33)\end{array}$ & $\begin{array}{c}-0.20 \\
(-1.85)\end{array}$ \\
\hline \multirow[t]{2}{*}{$\bar{R}^{2}$} & 2.80 & 4.48 & 4.03 & 2.82 & 6.18 & 9.71 & 0.43 & 1.26 & 3.35 \\
\hline & \multicolumn{9}{|c|}{ Panel C: $10 y r$ bond } \\
\hline$V R P^{S P X}$ & $\begin{array}{c}0.09 \\
(1.21)\end{array}$ & $\begin{array}{c}0.15 \\
(1.46)\end{array}$ & $\begin{array}{c}0.04 \\
(0.27)\end{array}$ & $\begin{array}{c}0.11 \\
(1.32)\end{array}$ & $\begin{array}{c}0.17 \\
(1.71)\end{array}$ & $\begin{array}{c}0.08 \\
(0.56)\end{array}$ & $\begin{array}{c}0.08 \\
(1.00)\end{array}$ & $\begin{array}{c}0.13 \\
(1.20)\end{array}$ & $\begin{array}{c}0.05 \\
(0.31)\end{array}$ \\
\hline$V R P^{5 y}$ & $\begin{array}{c}-0.16 \\
(-2.33)\end{array}$ & $\begin{array}{c}-0.19 \\
(-2.55)\end{array}$ & $\begin{array}{c}-0.20 \\
(-2.53)\end{array}$ & & & & & & \\
\hline$V R P^{10 y}$ & & & & $\begin{array}{c}-0.17 \\
(-2.50)\end{array}$ & $\begin{array}{c}-0.22 \\
(-2.81)\end{array}$ & $\begin{array}{c}-0.31 \\
(-3.25)\end{array}$ & & & \\
\hline$V R P^{30 y}$ & & & & & & & $\begin{array}{c}-0.04 \\
(-0.85)\end{array}$ & $\begin{array}{c}-0.06 \\
(-0.73)\end{array}$ & $\begin{array}{c}-0.16 \\
(-1.49)\end{array}$ \\
\hline \multirow[t]{2}{*}{$\bar{R}^{2}$} & 2.51 & 4.30 & 3.71 & 2.69 & 5.62 & 8.94 & 0.25 & 1.22 & 2.09 \\
\hline & \multicolumn{9}{|c|}{ Panel D: 30yr bond } \\
\hline$V R P^{S P X}$ & $\begin{array}{c}0.11 \\
(1.25)\end{array}$ & $\begin{array}{c}0.19 \\
(2.10)\end{array}$ & $\begin{array}{c}0.12 \\
(0.94)\end{array}$ & $\begin{array}{c}0.11 \\
(1.29)\end{array}$ & $\begin{array}{c}0.20 \\
(2.27)\end{array}$ & $\begin{array}{c}0.15 \\
(1.24)\end{array}$ & $\begin{array}{c}0.07 \\
(0.92)\end{array}$ & $\begin{array}{c}0.16 \\
(1.73)\end{array}$ & $\begin{array}{c}0.13 \\
(0.95)\end{array}$ \\
\hline$V R P^{5 y}$ & $\begin{array}{c}-0.14 \\
(-1.98)\end{array}$ & $\begin{array}{c}-0.17 \\
(-2.41)\end{array}$ & $\begin{array}{c}-0.22 \\
(-2.65)\end{array}$ & & & & & & \\
\hline$V R P^{10 y}$ & & & & $\begin{array}{c}-0.11 \\
(-1.62)\end{array}$ & $\begin{array}{c}-0.16 \\
(-1.62)\end{array}$ & $\begin{array}{c}-0.29 \\
(-2.39)\end{array}$ & & & \\
\hline$V R P^{30 y}$ & & & & & & & $\begin{array}{c}0.04 \\
(0.65)\end{array}$ & $\begin{array}{c}0.01 \\
(0.09)\end{array}$ & $\begin{array}{c}-0.16 \\
(-1.24)\end{array}$ \\
\hline $\bar{R}^{2}$ & 2.31 & 5.22 & 5.18 & 1.48 & 4.68 & 8.24 & 0.47 & 2.36 & 2.82 \\
\hline
\end{tabular}

Table IV. Return Predictability Regressions (Multivariate)

This table reports return predictability regressions of S\&P and bond futures excess returns on the equity and Treasury variance risk premia. $t$-statistics are reported in parentheses and computed using Newey and West (1987) standard errors with h-lags. The sample period is July 1991 to December 2013 for all regressions. Left and right hand variables are standardized. 


\begin{tabular}{|c|c|c|c|c|c|c|}
\hline & 1 & 2 & 3 & 4 & 5 & 6 \\
\hline & \multicolumn{6}{|c|}{ Panel A: Holding Period: $6 \mathrm{~m}$} \\
\hline \multirow[t]{2}{*}{$V R P^{30 y}$} & & & & -0.08 & -0.23 & -0.33 \\
\hline & & & & $(-1.02)$ & $(-2.53)$ & $(-4.00)$ \\
\hline \multirow[t]{2}{*}{$V R P^{S P X}$} & & & & -0.30 & -0.26 & -0.20 \\
\hline & & & & $(-4.32)$ & $(-3.92)$ & $(-2.67)$ \\
\hline \multirow[t]{2}{*}{ DY } & 0.28 & & & 0.31 & & \\
\hline & $(2.50)$ & & & $(3.12)$ & & \\
\hline \multirow[t]{2}{*}{$\mathrm{EP}$} & & 0.01 & & & 0.16 & \\
\hline & & $(0.04)$ & & & $(0.83)$ & \\
\hline \multirow[t]{2}{*}{ NTIS } & & & 0.31 & & & 0.42 \\
\hline & & & $(1.60)$ & & & $(2.20)$ \\
\hline \multirow[t]{2}{*}{$\bar{R}^{2}$} & 7.86 & 0.01 & 9.80 & 18.72 & 13.25 & 27.70 \\
\hline & \multicolumn{6}{|c|}{ Panel B: Holding Period: $12 \mathrm{~m}$} \\
\hline \multirow[t]{2}{*}{$V R P^{30 y}$} & & & & -0.11 & -0.31 & -0.42 \\
\hline & & & & $(-1.38)$ & $(-2.93)$ & $(-4.72)$ \\
\hline \multirow[t]{2}{*}{$V R P^{S P X}$} & & & & -0.24 & -0.17 & -0.11 \\
\hline & & & & $(-3.24)$ & $(-2.94)$ & $(-1.22)$ \\
\hline \multirow[t]{2}{*}{ DY } & 0.40 & & & 0.41 & & \\
\hline & $(3.15)$ & & & $(3.64)$ & & \\
\hline \multirow[t]{2}{*}{$\mathrm{EP}$} & & 0.04 & & & 0.18 & \\
\hline & & $(0.21)$ & & & $(1.10)$ & \\
\hline \multirow[t]{2}{*}{ NTIS } & & & 0.34 & & & 0.47 \\
\hline & & & $(1.50)$ & & & (2.67) \\
\hline $\bar{R}^{2}$ & 16.28 & 0.17 & 11.54 & 24.84 & 13.82 & 31.29 \\
\hline
\end{tabular}

Table V. Equity Return Predictability Regressions (Controls)

This table reports return predictability regressions of equity futures excess returns on the 30y Treasury variance risk premium, the equity variance risk premium, the log dividend yield (DY), the log earnings to price ratio (EP), and the net equity expansion (NTIS) from Goyal and Welch (2008). $t$-statistics are reported in parentheses and computed using Newey and West (1987) standard errors with h-lags. The sample period is July 1991 to December 2013 for all regressions. Left and right hand variables are standardized. 


\begin{tabular}{|c|c|c|c|c|c|c|c|c|}
\hline & 1 & 2 & 3 & 4 & 5 & 6 & 7 & 8 \\
\hline & \multicolumn{8}{|c|}{ Panel A: Holding Period: $6 \mathrm{~m}$} \\
\hline \multirow[t]{2}{*}{$V R P^{30 y}$} & & & & -0.05 & -0.09 & -0.17 & & \\
\hline & & & & $(-0.61)$ & $(-1.12)$ & $(-1.96)$ & & \\
\hline \multirow[t]{2}{*}{$V R P^{S P X}$} & & & & 0.13 & 0.12 & 0.20 & & \\
\hline & & & & $(1.63)$ & $(1.50)$ & $(2.17)$ & & \\
\hline \multirow[t]{2}{*}{ Slope } & 0.37 & & & 0.34 & & & & \\
\hline & $(3.28)$ & & & $(2.75)$ & & & & \\
\hline \multirow[t]{2}{*}{$\mathrm{CP}$} & & 0.42 & & & 0.39 & & & \\
\hline & & $(4.29)$ & & & $(4.16)$ & & & \\
\hline \multirow[t]{2}{*}{ LN1 } & & & -0.17 & & & -0.16 & & \\
\hline & & & $(-1.85)$ & & & $(-1.93)$ & & \\
\hline \multirow[t]{2}{*}{ LN2 } & & & 0.12 & & & 0.13 & & \\
\hline & & & $(2.69)$ & & & $(3.03)$ & & \\
\hline \multirow[t]{2}{*}{$E\left[V R P^{10 y} \mid\right.$ Slope $]$} & & & & & & & -0.37 & \\
\hline & & & & & & & $(-3.28)$ & \\
\hline \multirow{2}{*}{ error $^{\text {Slope }}$} & & & & & & & -0.01 & \\
\hline & & & & & & & $(-0.14)$ & \\
\hline \multirow{2}{*}{$E\left[V R P^{10 y} \mid \mathrm{CP}\right]$} & & & & & & & & -0.42 \\
\hline & & & & & & & & $(-4.27)$ \\
\hline \multirow[t]{2}{*}{ error $\mathrm{CP}$} & & & & & & & & -0.05 \\
\hline & & & & & & & & $(-0.65)$ \\
\hline \multirow[t]{2}{*}{$\bar{R}^{2}$} & 13.33 & 17.74 & 4.04 & 14.34 & 18.75 & 8.67 & 13.01 & 17.71 \\
\hline & \multicolumn{8}{|c|}{ Panel B: Holding Period: $12 \mathrm{~m}$} \\
\hline \multirow[t]{2}{*}{$V R P^{30 y}$} & & & & -0.13 & -0.14 & -0.26 & & \\
\hline & & & & $(-1.15)$ & $(-1.64)$ & $(-3.00)$ & & \\
\hline \multirow[t]{2}{*}{$V R P^{S P X}$} & & & & 0.05 & 0.02 & 0.12 & & \\
\hline & & & & $(0.36)$ & $(0.19)$ & $(0.87)$ & & \\
\hline \multirow[t]{2}{*}{ Slope } & 0.43 & & & 0.37 & & & & \\
\hline & $(3.00)$ & & & $(2.22)$ & & & & \\
\hline \multirow[t]{2}{*}{$\mathrm{CP}$} & & 0.54 & & & 0.49 & & & \\
\hline & & $(5.04)$ & & & $(4.79)$ & & & \\
\hline \multirow[t]{2}{*}{ LN1 } & & & -0.25 & & & -0.18 & & \\
\hline & & & $(-2.52)$ & & & $(-1.92)$ & & \\
\hline \multirow[t]{2}{*}{ LN2 } & & & 0.13 & & & 0.14 & & \\
\hline & & & $(3.39)$ & & & $(3.79)$ & & \\
\hline \multirow[t]{2}{*}{$E\left[V R P^{10 y} \mid\right.$ Slope $]$} & & & & & & & -0.43 & \\
\hline & & & & & & & $(-3.00)$ & \\
\hline \multirow[t]{2}{*}{ error ${ }^{\text {Slope }}$} & & & & & & & -0.10 & \\
\hline & & & & & & & $(-1.01)$ & \\
\hline \multirow{2}{*}{$E\left[V R P^{10 y} \mid \mathrm{CP}\right]$} & & & & & & & & -0.54 \\
\hline & & & & & & & & $(-4.93)$ \\
\hline error $\mathrm{CP}$ & & & & & & & & -0.13 \\
\hline & & & & & & & & $(-1.51)$ \\
\hline $\bar{R}^{2}$ & 18.76 & 28.68 & 7.53 & 19.33 & 29.94 & 12.96 & 19.44 & 30.15 \\
\hline
\end{tabular}

Table VI. 10y Treasury Futures Return Predictability Regressions (Controls)

This table reports return predictability regressions of 10y bond futures excess returns on the 10y Treasury variance risk premium, the equity variance risk premium, Slope (annualised GSW slope, 10y-1y), the Cochrane and Piazzesi (2005) factor (the CP factor), and the first two Ludvigson and $\mathrm{Ng}$ (2009) macro factors, LN1 and LN2. E[VRP $\left.P^{10 y} \mid \mathrm{Slope}\right]$ and $E\left[V R P^{10 y} \mid \mathrm{CP}\right]$ are the fitted component of the 10y Treasury variance risk premium on the Slope and Cochrane Piazzesi factors, respectively. error ${ }^{\text {Slope }}$ and error ${ }^{\mathrm{CP}}$ are the residuals from the regressions. $t$-statistics are reported in parentheses and computed using Newey and West (1987) standard errors with h-lags. The sample period is July 1991 to December 2013 for all regressions. Left and right hand variables are standardized. 


\begin{tabular}{|c|c|c|c|c|c|c|c|}
\hline & \multicolumn{3}{|c|}{ VRPs } & \multicolumn{2}{|c|}{ SB Corr } & \multicolumn{2}{|c|}{ VRP Corr } \\
\hline & $10 \mathrm{y}$ & $30 y$ & SP & $10 y$ & $30 y$ & $10 y$ & $30 y$ \\
\hline \multirow[t]{2}{*}{ Nominal Level } & -0.09 & 0.31 & 0.03 & 0.52 & 0.40 & 0.02 & -0.11 \\
\hline & $(-1.27)$ & $(3.53)$ & $(0.31)$ & $(4.45)$ & $(3.57)$ & $(0.15)$ & $(-0.72)$ \\
\hline \multirow[t]{2}{*}{ Nominal Slope } & -0.55 & -0.09 & -0.29 & -0.23 & -0.31 & -0.22 & -0.20 \\
\hline & $(-5.25)$ & $(-1.29)$ & $(-3.64)$ & $(-1.97)$ & $(-2.70)$ & $(-1.82)$ & $(-1.55)$ \\
\hline \multirow[t]{2}{*}{ IRP } & 0.72 & 0.66 & 0.61 & 0.52 & 0.56 & -0.33 & -0.38 \\
\hline & $(10.03)$ & $(7.01)$ & $(3.77)$ & $(4.29)$ & $(4.44)$ & $(-3.23)$ & $(-3.18)$ \\
\hline $\bar{R}^{2}$ & $48 \%$ & $44 \%$ & $29 \%$ & $42 \%$ & $36 \%$ & $22 \%$ & $24 \%$ \\
\hline
\end{tabular}

Table VII. Real versus Nominal Risks: Inflation Protected Bonds

Table reports contemporaneous OLS estimates of variance risk premia (VRPs), stock-bond correlation (SB Corr), and variance risk premia correlations (VRP Corr) on the first two principal components of the nominal term structure computed using 2- to 10-year maturities. The first principal component is the Real Level and the second principal component is the Real Slope which is rotated such that a positive shock to this factor raises long term yields and lowers short term yields. IRP is the inflation risk premium. $t$-statistics are reported in parentheses and computed using Newey and West (1987) standard errors with 12-lags. The sample period is January 2000 to December 2013. Left and right hand variables are standardized. 


\begin{tabular}{|c|c|c|c|c|c|c|c|}
\hline & \multicolumn{3}{|c|}{ VRPs } & \multicolumn{2}{|c|}{ SB Corr } & \multicolumn{2}{|c|}{ VRP Corr } \\
\hline & $10 y$ & $30 y$ & SP & $10 y$ & $30 y$ & $10 y$ & $30 y$ \\
\hline \multirow[t]{2}{*}{ Real Level } & -0.04 & 0.37 & 0.11 & 0.55 & 0.43 & 0.02 & -0.11 \\
\hline & $(-0.57)$ & $(4.05)$ & $(0.80)$ & $(4.80)$ & $(3.62)$ & $(0.16)$ & $(-0.69)$ \\
\hline \multirow[t]{2}{*}{ Real Slope } & -0.53 & -0.10 & -0.20 & -0.01 & -0.08 & -0.19 & -0.15 \\
\hline & $(-5.29)$ & $(-1.36)$ & $(-2.11)$ & $(-0.07)$ & $(-0.63)$ & $(-1.49)$ & $(-1.05)$ \\
\hline \multirow[t]{2}{*}{ IRP } & 0.43 & 0.45 & 0.41 & 0.17 & 0.21 & -0.46 & -0.44 \\
\hline & $(5.59)$ & $(4.44)$ & $(2.67)$ & $(1.61)$ & $(1.93)$ & $(-6.96)$ & $(-5.60)$ \\
\hline $\bar{R}^{2}$ & $50 \%$ & $46 \%$ & $26 \%$ & $39 \%$ & $30 \%$ & $21 \%$ & $23 \%$ \\
\hline
\end{tabular}

Table VIII. Real versus Nominal Risks: Nominal Bonds (TIPS sample)

Table reports contemporaneous OLS estimates of variance risk premia (VRPs), stock-bond correlation (SB Corr), and variance risk premia correlations (VRP Corr) on the first two principal components of the real term structure computed using 2- to 10-year maturities. The first principal component is the Real Level and the second principal component is the Real Slope which is rotated such that a positive shock to this factor raises long term yields and lowers short term yields. IRP is the inflation risk premium. $t$-statistics are reported in parentheses and computed using Newey and West (1987) standard errors with 12-lags. The sample period is January 2000 to December 2013. Left and right hand variables are standardized. 